\title{
əThe Impact of Anthropogenic Forcing and Natural Processes on Past, Present, and Future Rainfall over Victoria, Australia
}

\author{
SURENDRA P. RAUNIYAR \\ Climate Change and Variability Program, Science to Services, Australian Bureau of Meteorology, Melbourne, \\ Victoria, Australia \\ SCOTT B. POWER \\ Climate Change and Variability Program, Science to Services, Australian Bureau of Meteorology, \\ and ARC Centre of Excellence for Climate Extremes, and School of Earth, Atmosphere and Environment, \\ Monash University, Melbourne, Victoria, Australia
}

(Manuscript received 10 October 2019, in final form 2 June 2020)

\begin{abstract}
Cool-season (April to October) rainfall dominates the annual average rainfall over Victoria, Australia, and is important for agriculture and replenishing reservoirs. Rainfall during the cool season has been unusually low since the beginning of the Millennium Drought in 1997 ( $\sim 12 \%$ below the twentieth-century average). In this study, 24 CMIP5 climate models are used to estimate 1) the extent to which this drying is driven by external forcing and 2) future rainfall, taking both external forcing and internal natural climate variability into account. All models have preindustrial, historical, and twenty-first-century (RCP2.6, RCP4.5, and RCP8.5) simulations. It is found that rainfall in the past two decades is below the preindustrial average in two-thirds or more of model simulations. However, the magnitude of the multimodel median externally forced drying is equivalent to only $20 \%$ of the observed drying (interquartile range of $40 \%$ to $-4 \%$ ), suggesting that the drying is dominated by internally generated rainfall variability. Underestimation of internal variability of rainfall by the models, however, increases the uncertainties in these estimates. According to models the anthropogenically forced drying becomes dominant from 2010 to 2029, when drying is evident in over $90 \%$ of the model simulations. For the $2018-37$ period, it is found that there is only a $\sim 12 \%$ chance that internal rainfall variability could completely offset the anthropogenically forced drying. By the late twenty-first century, the anthropogenically forced drying under RCP8.5 is so large that internal variability appears too small to be able to offset it. Confidence in the projections is lowered because models have difficulty in simulating the magnitude of the observed decline in rainfall.
\end{abstract}

\section{Introduction}

Victoria experiences large variability in rainfall, on interannual through to multidecadal time scales (Power et al. 1999a,b; DELWP 2016a; Timbal et al. 2016; Hope et al. 2017). The instrumental records, which began in the 1850s, as well as paleoclimate proxy records from a range of sources (Gallant and Gergis 2011; Gergis et al. 2012) show that Victoria has experienced numerous flooding and several drought episodes. Three prolonged periods of below-

¿ Denotes content that is immediately available upon publication as open access.

Corresponding author: Surendra Rauniyar, surendra.rauniyar@ bom.gov.au average rainfall occurred during the instrumental period (Timbal and Fawcett 2013): the Federation Drought (18961905), the World War II Drought (WWII; 1936-45), and the Millennium Drought (MD; 1997-2009; Fig. 1), each with different characteristics (Verdon-Kidd and Kiem 2009; Timbal and Fawcett 2013). Recent studies (Grose et al. 2015a; Timbal et al. 2016; Hope et al. 2017) show that Victoria has experienced an annual rainfall decline of approximately $2 \mathrm{~mm}$ decade $^{-1}$ since 1960 , despite the occurrence of several wet years during the 1970s, in 2010-11, and more recently in 2016 . This decline was driven by a downward trend in "cool-season" (April to October) rainfall. The warm and cool seasons for Victoria consist of the months in which long-term monthly average temperatures are above and below the annual average temperature (Timbal et al. 2016). On average, Victoria receives about two-thirds of its 

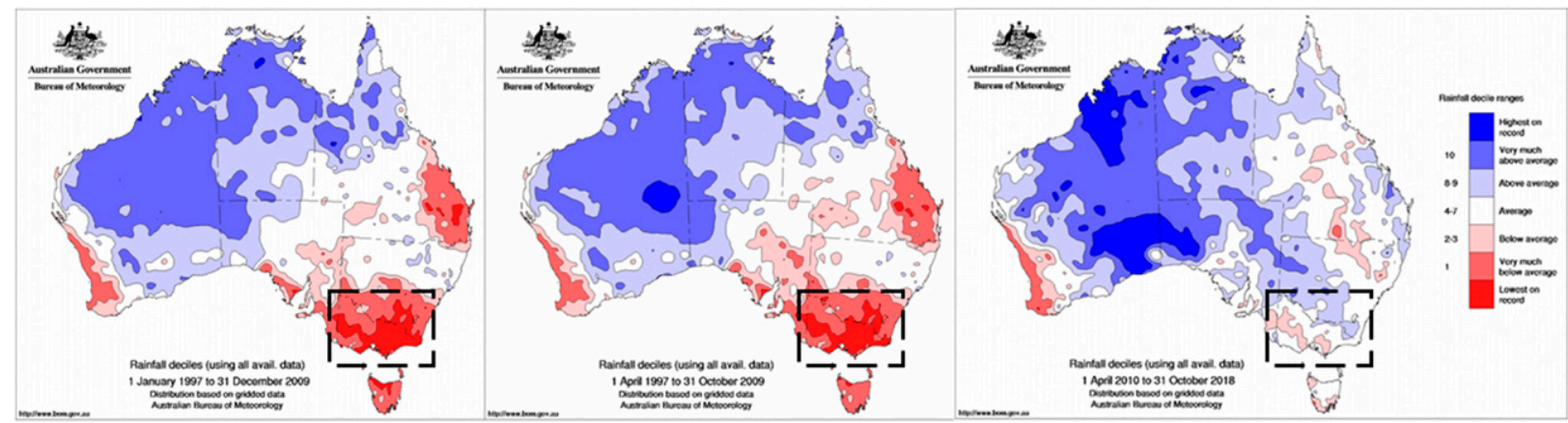

FIG. 1. (left) Annual rainfall deciles map for the Millennium Drought (1997-2009) using the 1900-2018 period as climatology. (middle) As in the left panel, but for the cool season (April-October) only. (right) As in the middle panel, but for the post-Millennium Drought period (2010-18). Victoria state, the region of interest for this study, is located inside the rectangular box.

annual rainfall during the cool season. Cool-season rainfall is also important for many crops and for replenishing reservoirs across the state. Streamflow reductions can be 2-3 times the rainfall declines, which means heightened implications for reservoir stores (DELWP 2016b; Potter et al. 2016; Timbal et al. 2016). Saft et al. (2015) found that the amount of runoff for the same amount of rainfall has also reduced during the MD across a number of catchments compared with the historical rainfall-runoff relationship prior to 1997.

Research undertaken during the South-Eastern Australia Climate Initiative (SEACI) Phase 1 (CSIRO 2010; 2006-09) and Phase 2 (CSIRO 2012; 2009-12) and during the Victorian Climate Initiative (VicCI; 2013-16; Hope et al. 2017) showed that the MD was the most severe protracted drought of the instrumental period. It was also the longest drought observed in the historical record (Kiem and Verdon-Kidd 2010; Grant et al. 2013; Timbal and Fawcett 2013; Cai et al. 2014; DELWP 2016b; Dey et al. 2019). It lasted for 13 years (1997-2009) with particularly large rainfall shortages compared to any previous historical droughts. The MD was characterized by a large decline in late autumn and early winter rainfall, whereas the previous droughts exhibited a larger reduction in winter-spring rainfall (CSIRO 2012). In addition, there has been a significant warming trend in Victoria over the last 100 years, and the MD thus occurred in warmer conditions than the earlier droughts (Timbal et al. 2016). The lower rainfall prior to the start of the runoff season (i.e., winter) contributed to a larger than anticipated decline in streamflow $(25 \%-75 \%$ relative to the pre-1997 period) during the traditional filling season for water storages in Victoria (Timbal et al. 2009; Potter et al. 2016). In spring/summer of 2010/11 and 2011/12, La Niña-driven extreme rainfall resulted in widespread flooding across the region (and throughout Australia), which ended the MD. During these periods, all the three key large-scale drivers for rainfall, namely, El Niño-Southern Oscillation (ENSO), the Indian Ocean dipole (IOD), and the southern annular mode (SAM), were in phases historically linked to wet conditions in southeastern Australia (Hendon et al. 2014; Hope et al. 2017), causing the above-average annual rainfall totals across the region. However, the cool-season rainfall continued to be below average even after the MD broke (Fig. 1). These characteristics are likely to place the rainfall since the start of the MD outside what would be expected based on internal climate variability only, which is assessed below. Internal variability is due to instabilities that occur naturally within the climate system itself, without any form of external forcing (Hawkins and Sutton 2011; Kirtman et al. 2013). On the other hand, the instrumental period is relatively short (only 119 years) and it is possible that previous 20 -yr periods were as dry as or drier than the recent period, during preinstrumental times. Paleoclimate studies have addressed this issue and they concluded that there have indeed been other significant drought periods (Gergis et al. 2012; Freund et al. 2017). Other studies suggest that there may have been longer dry periods in the last 600 years (Ho et al. 2015).

Previous studies (e.g., CSIRO 2010, 2012; Cai et al. 2014; Grose et al. 2015a; Timbal et al. 2016; Hope et al. 2017, 2015; Delworth and Zeng 2014; DELWP 2016a) examined projections for Victorian rainfall and suggest a greater likelihood of a drier Victorian climate in the future as a likely response to increased anthropogenic forcings. For example, research reported in VicCI (Hope et al. 2017) under a scenario of high greenhouse gas emissions called representative concentration pathway 8.5 (RCP8.5; van Vuuren et al. 2011) in CMIP5 models for the late twenty-first century, relative to 1986-2005 projected a decline in cool-season rainfall of $-8 \%$ in Victoria and $-15 \%$ across southwest Victoria. Better performing models exhibited a stronger rainfall decline 
for all Victoria under the same scenario, from a median of $-8 \%$ to $-14 \%$. Grose et al. (2015a), using the same model output, found that almost all CMIP5 models project a reduction of mean annual rainfall across the Southern Slopes, which largely consists of southern Victoria. They also concluded that natural climate variability may remain "the major driver" of rainfall changes by 2030 even as anthropogenic changes become apparent. Grose et al. (2015a) also found that there is high confidence in projected rainfall decreases in winter and spring in the Southern Slopes under higher emissions (RCP8.5) from 2050 to 2090, but with some differences within the region and between seasons. They suggest that by 2090, spring rainfall is projected to decrease across the Southern Slopes by around $-25 \%$ to $+5 \%$ under RCP 4.5 and $-45 \%$ to $+5 \%$ under RCP 8.5 relative to 1986-2005. Timbal et al. (2015) found that the changes in mean rainfall by 2030 relative to 1986-2005 across the Natural Resources Management (NRM) Murray Basin Cluster, which largely consists of northern Victoria, is small compared to natural variability. They found that the changes in mean rainfall is around $-10 \%$ to $+5 \%$ annually, and around $-15 \%$ to $+10 \%$ in winter, and $-15 \%$ to $+15 \%$ in summer under all the RCP scenarios they considered. They suggested that by 2090, changes in winter rainfall span $-20 \%$ to $+5 \%$ under RCP 4.5 and $-40 \%$ to $+5 \%$ under RCP 8.5 , and those in summer rainfall span $-15 \%$ to $+10 \%$ under RCP4.5 and $-15 \%$ to $+25 \%$ under RCP8.5. Recent studies have found similar results (e.g., Hope et al. 2017; Cai et al. 2014; Timbal et al. 2017; Potter et al. 2018).

On the other hand, there is no clear agreement among the models on the sign of future rainfall change during summer. Also, most models project little change in autumn across the Southern Slopes Cluster (Grose et al. 2015a). This contrasts with observed post-1960 declining trends in autumn having been more significant than those for spring. There are known deficiencies in the simulation of the current climate in autumn (CSIRO and Bureau of Meteorology 2015). This observation-model discrepancy was explored in Hope et al. (2015); it lowers the confidence we have in both projections and in our ability to quantify the relative importance of anthropogenic forcing and natural changes in the recent multidecadal drying that has occurred in Victoria.

While an important component of the IPCC assessments has been the attribution of observed trends to anthropogenic forcing, there were no attribution studies for the rainfall trends across southern Australia reported in the last assessment (IPCC 2013). Timbal et al. (2006) assessed two ensembles of one climate model forced with natural variability (solar variability and volcanic eruptions) and all forcings (increasing atmospheric greenhouse gases, aerosols, and the growth of the Antarctic ozone hole) to investigate the rainfall decline in southwest Western Australia that began in the late 1960s. They found that anthropogenic forcing was needed for the climate models to simulate the decline, but also that downscaling helped clarify the signal, because predictors including pressure presented a clearer signal over this region than the rainfall produced directly by the climate models. Similar approaches are presented in Timbal et al. (2010) for all of Australia, including Victoria. Again, while the signal in the pressure is clearer than the rainfall directly from the climate model, they found that anthropogenic forcing enhanced the rainfall decline in Victoria over recent decades. In contrast, Hoerling et al. (2010) found that the ensemble mean of 23 CMIP3 models exhibits the opposite of the observed annual rainfall trends during 1977-2006 over eastern Australia in response to external radiative forcing. They also found that the recent 30 years' rainfall change over Australia is not consistent with SST forcing alone. Delworth and Zeng (2014) analyzed the control simulation and ensembles that incorporates different combinations of atmospheric compositions from a high-resolution version of the Geophysical Fluid Dynamics Laboratory (GFDL) global climate model (CM2.5; Delworth et al. 2012) to assess whether the observed trends in autumn and winter rainfall over south and southwest Australia can be attributed to human-induced climate change. They found that observed decline in rainfall over southeastern Australia for the 1991-2012 period relative to 1901-90 is unusual, but not clearly separable from internal climate variability. The lack of attribution studies analyzing the results from climate models with different forcing over Victoria is a clear gap in the literature that we will partially address in the current study as to date no attribution studies have been conducted using CMIP5 models.

Rauniyar et al. (2019) recently synthesized relevant literature (e.g., CSIRO 2010, 2012; Cai et al. 2014; Grose et al. 2015a; Timbal et al. 2016; Hope et al. 2017, 2015; Grose et al. 2017) that sheds light on the cause of the drying over Victoria. They concluded that

(i) aspects of the drying in parts of Victoria are unusual in terms of the historical record;

(ii) the drying observed over Victoria appears to have been partly caused by anthropogenic climate change and partly caused by natural climate variability;

(iii) a major focus for the research to date for southeast Australia has been on the characteristics of the drying and the impact of anthropogenic forcing on drivers of climate variability in Victoria [e.g., ENSO, the Subtropical Ridge (STR), the Hadley circulation, the SAM, the IOD, and the interdecadal Pacific oscillation];

(iv) research directly examining the changes in Victorian precipitation in climate models under anthropogenic and natural forcing has been limited; 
(v) the relative importance of anthropogenic forcing and natural climate variability to the recent drying is unclear (anthropogenic climate change has likely exacerbated drying from natural variability, although the magnitude of the anthropogenic drying is uncertain, and further research is needed to clarify the magnitude of the contribution); and

(vi) there is scope to provide an estimate of the magnitude of the contribution of anthropogenic forcing to the recent multidecadal drying through the use of climate models and observations.

The main objective of this study is to build on the earlier research to estimate the relative importance of internal variability and external forcing in the recent drying of cool-season rainfall by analyzing the observed and simulated rainfall over Victoria. We will also address the following questions:

1) How unusual is the observed recent drying since the beginning of the MD in 1997 over Victoria?

2) Did GHGs contribute to the twentieth-century drying? Do models simulate the decrease in rainfall during the recent (1997-2018) period, and if they do, how much of the drying is due to external forcing?

3) Do models project a decrease in rainfall in the near future (2020-40) and toward the end of the twenty-first century (2081-2100) under all three RCP scenarios, and if so then how large is the simulated drying relative to the preindustrial variability and to major observed droughts like the MD? When does the impact of global GHG emissions on rainfall become clear? That is, when does external forcing "expel" rainfall beyond its preindustrial and historical range (Power 2014)?

4) What is the expected combined impact of both external forcing and internal variability on Victorian rainfall over coming decades?

As far as we are aware, questions 2-4 have not been fully addressed previously. Regarding question 1, it was partially addressed by SEACI (CSIRO 2012), although how unusual the recent cool-season rainfall decline is in terms of its own stochastic variability has not been estimated. The remaining part of the paper is organized as follows: a brief description of data, climate models, and methods used is provided in section 2. Results are presented in section 3, including the results for the model evaluation. Section 4 summarizes the major findings of this study, discusses possible explanations for the observed results, and suggests future work.

\section{Data, climate models, and methods}

In this study, we use the observed rainfall data for the period 1900-2018 to analyze the past climate variability and change over Victoria. This rainfall product is available at its original resolution of $0.05^{\circ} \times 0.05^{\circ}$ spatially at daily time resolution from the Bureau of Meteorology under the Australian Water Availability Project (AWAP; Jones et al. 2009). We converted this data to monthly resolution and applied the conservative interpolation method (Jones 1999; Rauniyar et al. 2017) to regrid them to $1.5^{\circ} \times 1.5^{\circ}$ spatial resolution, which is closer to the resolution of the climate models. All the key statistics of observed rainfall are computed by area-averaging (Victorian average) of the reprocessed data and the same is used to assess the climate models used in this study.

Similarly, monthly rainfall simulations from a number of global coupled climate models from phase 5 of the Coupled Model Intercomparison Project (CMIP5; Taylor et al. 2012) are used to understand the role of anthropogenic forcings in the past and future changes in Victorian rainfall. For this project, we use the long-term model simulations under the preindustrial control (piCTL) runs with at least 500 years of simulations (see Table 1) unless otherwise stated. In the piCTL experiments, the atmospheric concentrations of GHGs, aerosols, ozone, and solar irradiance are prescribed (fixed) at the preindustrial level (year 1850). Hence, piCTL simulations are very useful to estimate the modeled range of internal climate variability statistics (Delworth and Zeng 2014). Similarly, historical simulations with three different forcings (i.e., all, GHG, and natural) are used for the period 1900-2005 to distinguish the role of natural and anthropogenic factors in the observed change of rainfall. Historical simulations with all forcings (histALL) have time-dependent atmospheric composition due to both anthropogenic and volcanic influences, solar forcing, and emissions or concentrations of short-lived species and natural and anthropogenic aerosols or their precursors, as well as land use. The historical GHG-only (histGHG) and naturalonly (histNAT) simulations are similar to the histALL, except that they include the time-varying greenhouse gas forcings only and natural forcings (e.g., solar variability, volcanoes, aerosols) only. Intercomparison of simulated rainfall under these experiments could provide an answer on how the Victorian rainfall responds to the different atmospheric forcings. Furthermore, we also use future projections of rainfall for the twenty-first century under three RCPs (i.e., RCP2.6, RCP4.5, and RCP8.5), which vary markedly in the amount of greenhouse gas emitted, or drawn from the atmosphere, over the coming century (van Vuuren et al. 2011). The labels for the RCPs provide a rough estimate of the radiative forcing in the year 2100 relative to preindustrial condition. For example, the RCP2.6 represents the lowest-emission scenario, which has estimated a radiative forcing of approximately $2.6 \mathrm{~W} \mathrm{~m}^{-2}$ at the year 2100 . 
TABLE 1. Description of the models under different CMIP5 experiments that are used in this study. 35 models under preindustrial runs have at least 200 years of simulations. The number reduces to 26 models with at least 500 years of simulation $(\times$ in the piCTL column). Similarly, 48 models provide historical simulation using all-forcing for the period 1900-2005, but out of this only 18 and 16 models have historical simulations under natural-only and GHG-only forcings, respectively. Out of 48 historical all forcings model, only 26 models have future projections under all the three RCP scenarios, 38 models have them under RCP8.5 and RCP4.6 scenarios only, and 40 models have them for the RCP8.5 scenario only. Most of the analysis in this paper is based on 24 models (in bold) that have at least 500 years of piCTL runs and also have simulations under historical all-forcing, RCP4.5, and RCP8.5 scenarios. Model poor performance score is copied from appendix 3 of Timbal et al. (2016), which shows the number of times a model scored low on various skill metrics [for details see Table 5.6.1, p. 76, in CSIRO and Bureau of Meteorology (2015)] and are used to recompute the multidecadal statistics by selecting the appropriate models only (performance score less than 3).

\begin{tabular}{|c|c|c|c|c|c|c|c|c|}
\hline \multirow[b]{2}{*}{ Model names } & \multirow[b]{2}{*}{ piCTL } & \multicolumn{3}{|c|}{ Historical } & \multicolumn{3}{|c|}{ RCPs } & \multirow[b]{2}{*}{ Poor performance } \\
\hline & & ALL & NAT & GHG & 8.5 & 4.5 & 2.6 & \\
\hline ACCESS1.0 & $x$ & $\times$ & & & $x$ & $\times$ & & 1 \\
\hline ACCESS1.3 & $\times$ & $\times$ & & & $\times$ & $\times$ & & 2 \\
\hline BCC-CSM1.1 & $\times$ & $\times$ & $x$ & $x$ & $\times$ & $\times$ & $x$ & 0 \\
\hline BCC-CSM1.1-m & + & $\times$ & & & $\times$ & $\times$ & $\times$ & 0 \\
\hline BNU-ESM & $x$ & $x$ & $\times$ & & $x$ & $\times$ & $x$ & 3 \\
\hline CanESM2 & $x$ & $\times$ & $\times$ & $\times$ & $\times$ & $\times$ & $\times$ & 1 \\
\hline CCSM4 & $x$ & $x$ & $x$ & $\times$ & $x$ & $\times$ & $x$ & 1 \\
\hline CESM1-BGC & $\times$ & $x$ & & & $\times$ & $\times$ & & 1 \\
\hline CESM1-CAM5 & + & $x$ & & & $\times$ & $\times$ & $x$ & 0 \\
\hline CESM1-CAM5.1-FV2 & & $\times$ & & & & & & - \\
\hline CESM1-FASTCHEM & + & $x$ & & & & & & - \\
\hline CESM1-WACCM & + & $x$ & & & & & & 3 \\
\hline CMCC-CESM & & $x$ & & & $\times$ & & & 1 \\
\hline CMCC-CM & + & $\times$ & & & $\times$ & $x$ & & 0 \\
\hline CMCC-CMS & $x$ & $x$ & & & $x$ & $x$ & & 1 \\
\hline CNRM-CM5 & $\times$ & $x$ & $x$ & $x$ & $\times$ & $x$ & $x$ & 0 \\
\hline CNRM-CM5.2 & & $x$ & & & & & & - \\
\hline CSIRO-Mk3.6.0 & $\times$ & $x$ & $x$ & $x$ & $\times$ & $\times$ & $\times$ & 2 \\
\hline CSIRO-Mk3L-1.2 & $x$ & & & & & & & - \\
\hline EC-EARTH & & $x$ & & & $x$ & & & - \\
\hline FGOALS-g2 & $x$ & $x$ & $x$ & $x$ & $\times$ & $x$ & $x$ & - \\
\hline FGOALS-s2 & $\times$ & $\times$ & & & $\times$ & $x$ & $\times$ & - \\
\hline FIO-ESM & & $x$ & & & $\times$ & $x$ & $\times$ & - \\
\hline GFDL-CM2p1 & & $x$ & & & & & & - \\
\hline GFDL CM3 & $x$ & $x$ & $x$ & $x$ & $\times$ & $x$ & $x$ & 1 \\
\hline GFDL-ESM2G & $x$ & $x$ & & & $x$ & $x$ & $x$ & 3 \\
\hline GFDL-ESM2M & $x$ & $\times$ & $x$ & $\times$ & $\times$ & $\times$ & $\times$ & 0 \\
\hline GISS-E2-H & + & $x$ & $x$ & $\times$ & $\times$ & $x$ & $x$ & 4 \\
\hline GISS-E2-H-CC & & $\times$ & & & $\times$ & $\times$ & & 3 \\
\hline GISS-E2-R & & $\times$ & $x$ & $\times$ & $x$ & $x$ & $x$ & 3 \\
\hline GISS-E2-R-CC & & $\times$ & & & $\times$ & $\times$ & & - \\
\hline HadCM3 & & $x$ & & & & & & 2 \\
\hline HadGEM2-AO & & $\times$ & & & $\times$ & $\times$ & $\times$ & - \\
\hline HadGEM2-CC & & $x$ & & & $\times$ & $x$ & & 0 \\
\hline HadGEM2-ES & $x$ & $\times$ & $\times$ & $x$ & $\times$ & $\times$ & $\times$ & 1 \\
\hline INM-CM4 & $\times$ & $\times$ & & & $x$ & $\times$ & & 3 \\
\hline IPSL-CM5A-LR & $x$ & $\times$ & $x$ & $x$ & $\times$ & $\times$ & $x$ & 3 \\
\hline IPSL-CM5A-MR & + & $x$ & $x$ & & $\times$ & $\times$ & $\times$ & 3 \\
\hline IPSL-CM5B-LR & + & $\times$ & & & $\times$ & $x$ & & 1 \\
\hline MIROC-ESM & $x$ & $x$ & $x$ & $x$ & $\times$ & $x$ & $x$ & 5 \\
\hline MIROC-ESM-CHEM & & $x$ & $x$ & $x$ & $\times$ & $x$ & $x$ & 4 \\
\hline MIROC5 & $\times$ & $\times$ & & & $\times$ & $x$ & $x$ & 0 \\
\hline MPI-ESM-LR & $x$ & $x$ & & & $\times$ & $x$ & $x$ & 1 \\
\hline MPI-ESM-MR & $x$ & $x$ & & & $\times$ & $x$ & $x$ & 1 \\
\hline MPI-ESM-P & $x$ & $x$ & & & & & & 1 \\
\hline MRI-CGCM3 & $x$ & $x$ & $\times$ & $x$ & $\times$ & $x$ & $\times$ & 1 \\
\hline MRI-ESM1 & & $x$ & & & & & & - \\
\hline NorESM1-M & $x$ & $x$ & $x$ & $x$ & $x$ & $x$ & $x$ & 1 \\
\hline NorESM1-ME & + & $x$ & & & $\times$ & $x$ & $x$ & 1 \\
\hline Total & 35 & 48 & 18 & 16 & 40 & 38 & 28 & 37 \\
\hline
\end{tabular}


For all the experiments described above, we use only the first realization, initialization, and physical parameterization (i.e., r1i1p1) run of each model (see Table 1) to avoid weighting models with more than one simulation. Each CMIP5 experiment has a different number of model simulations as listed in Table 1, but we selected only 24 models that have in common simulated rainfall across the piCTL, histALL, RCP8.5, and RCP4.5 scenarios. Similarly, only 19 models are common under the piCTL, histALL, and $\mathrm{RCP} 2.6$ scenarios and the number is further reduced to 13 for the piCTL, histALL, histGHG, and histNAT scenarios. Furthermore, the models also differ in their spatial resolution, so we interpolated them using the conservative mapping approach to a common $1.5^{\circ} \times 1.5^{\circ}$ grid resolution and used to compute the area-averaged rainfall time series for Victoria prior to any analysis.

To analyze the rarity of occurrence of the recent decline in rainfall in terms of its own variability, we perform bootstrap resampling (Efron and Tibshirani 1994). This is done by random resampling of the full historical period of area-averaged cool-season rainfall (119 years: 1900-2018) 10000 times and each time the difference between average rainfall of the last 22 years and the average of the first 60 years is computed. These 10000 samples of mean rainfall differences are used to compute the relative frequency distribution. Relative frequency distributions are also calculated for the percentage differences and for difference scaled by the interannual standard deviation of rainfall variability over the first 60 years. This gives a distribution against which the recent decline can be compared to compute its chance of occurrence relative to the statistical variability. We choose the first six decades as a reference assuming that the influence of climate change, if any, on rainfall variability is less in earlier decades. Since the model simulations under historical forcings cover the 1850-2005 period only, we extended the histALL to 2018 by augmenting the corresponding model RCP8.5 data over the period 2006-18 to directly compare with the observational period. We estimated the possible range of multidecadal rainfall variability by computing the changes in rainfall in 20 -yr blocks relative to the statistics of 500-yr-long piCTL simulations. This provides us an opportunity to estimate 600 different multidecadal rainfall change situations (i.e., 24 models $\times 25$ numbers of 20 -yr blocks in 500 years of piCTL), which are then used to compute the relative frequency distribution. This distribution can be used to represent the multidecadal changes that can arise due to internal climate variability alone. Finally, we computed the multidecadal rainfall changes relative to 500 years of piCTL statistics for every 20-yr block from 1900-19 to 2081-2100 under histALL simulations combined with the RCP scenarios. These values are then compared against the distribution of multidecadal piCTL rainfall changes to estimate the statistics as discussed in section 3d. For example, we calculate an estimate of the relative proportion of the rainfall decline that was due to external forcing, and also the timing of when the signal due to external forcing fully emerges from the internal variability.

\section{Results}

\section{a. General characteristics}

Historical records show that rainfall over Victoria (Australia) exhibits a great deal of variability. The annual rainfall map (Fig. 2a) shows that areas associated with higher elevations receive the highest amount of rainfall, followed by the southern coastal regions. Substantially less rainfall occurs over the northwest of Victoria. Figure $2 b$ shows that the rainfall over Victoria occurs predominantly in the "cool season" (defined here as April to October) compared to the "warm season" (Fig. 2c; November to March), except in the eastern part of the state where a weaker seasonal cycle dominates. The long-term average annual rainfall (19002018) across Victoria is approximately $655 \mathrm{~mm} \mathrm{yr}^{-1}$ with interannual standard deviation of $119 \mathrm{~mm} \mathrm{yr}^{-1}$ and cool season on average contributes two-thirds $(66 \%)$ of this amount. However, annual rainfall varies considerably from year to year, from decade to decade, and on longer time scales (Fig. 3) in response to a complex interplay of several large-scale climate drivers and other sources of natural variability and potentially climate change. Victoria has experienced below-average rainfall on average since the mid-1970s (blue dashed line in Fig. 3). Despite the occurrence of several wet years during the 1970s, in 2010-11, and more recently in 2016, the long-term annual mean rainfall exhibits a negative trend $\left(2 \mathrm{~mm} \mathrm{decade}^{-1}\right)$. Figure 3 also shows that the low annual rainfall in recent decades is dominated by the low cool-season rainfall (Fig. 3b), which has declined by approximately $12 \%$ since the beginning of the MD in 1997 relative to the twentieth-century climatology. In comparison, the change in warm-season rainfall (Fig. 3c) in recent decades is negligible (less than $+1 \%$ ). Hence, for the remainder of this paper, we primarily present and discuss the characteristics of the cool-season rainfall only.

\section{b. Multidecadal variability in rainfall}

It is well known that Victorian rainfall exhibits multidecadal variability (Power et al. 1999b). To examine whether the characteristics of rainfall in recent decades are similar or different compared to any other multidecadal periods or the long-term climatology, we compute the relative frequency distributions using coolseason monthly mean rainfall for different 20 -yr blocks from 1900-19 to 1997-2018 as shown in the legend of Fig. 4. As expected, the multidecadal distributions or median values 

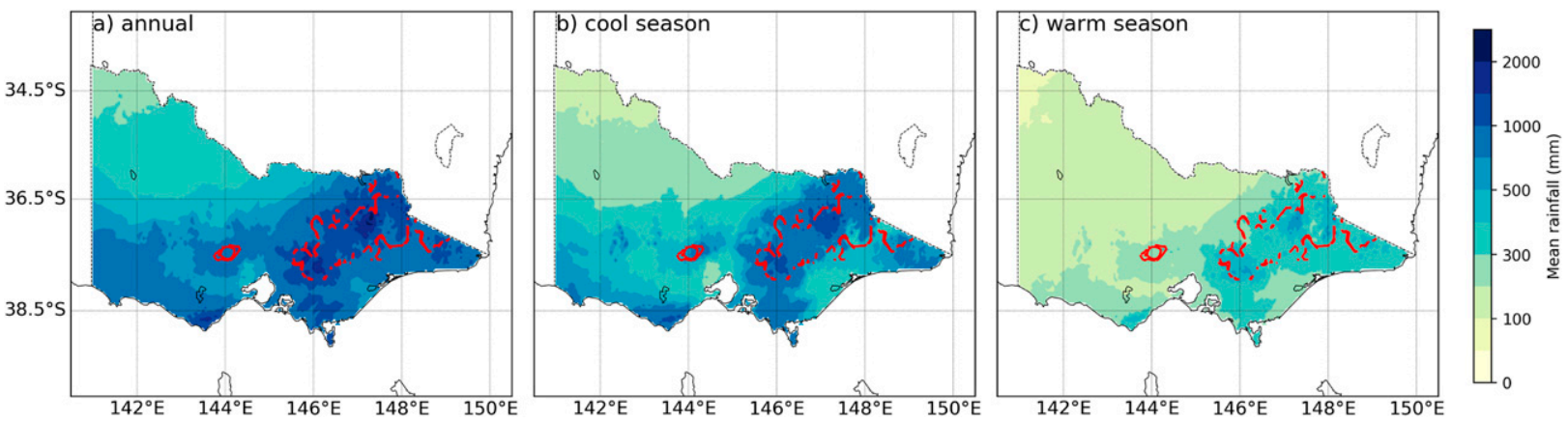

FIG. 2. Spatial distribution of mean (a) annual, (b) cool-season (April-October), and (c) warm-season (November-March) rainfall $(\mathrm{mm})$ across Victoria using Australian Water Availability Project (AWAP) $5 \mathrm{~km} \times 5 \mathrm{~km}$ gridded rainfall product for the 1900-2018 period. Elevations greater than $500 \mathrm{~m}$ are shown in red contours.

differ between the periods shown, confirming the existence of decade to decade variations in rainfall. Nevertheless, the variations among the twentieth-century distributions are not substantially different from each other (as shown by the median rainfall of these periods; vertical lines in varying colors). We found that none of the differences between periods prior to 1997-2018 are statistically significant at $95 \%$ level based on a two-sample Kolmogorov-Smirnov test. In contrast, the distribution of the recent decades (1997-2018) differs substantially ( $p$ value $<0.05$, using the same test) from the rest of the multidecadal distributions, including the distribution of the twentieth century. In fact, the distribution of cool-season rainfall for 1997-2018 has shifted to the left (i.e., to a mean lower monthly rainfall value) compared to the rest of the distributions and a clear shift in the frequency of rainfall around $60 \mathrm{~mm}$ month $^{-1}$ can be seen (Fig. 4). In general, the 1997-2018 period experienced fewer cool seasons with rainfall above the median of the twentieth century $\left(60 \mathrm{~mm} \mathrm{month}^{-1}\right)$ whereas the frequency of the below median increased. This change can be explained by a reduction in the frequency of rainy days during the cool season (Guerreiro et al. 2018).

It is possible that the drier conditions over Victoria since the start of the MD in 1997 may indicate a climate shift as observed in southwest Western Australia (Hope et al. 2010). It is also possible that the observed drying trend is temporary and might have been caused by the natural internal climate variability alone. As a first step toward addressing these issues we first assess the degree to which the drying is unusual. To do this, we perform Monte Carlo (bootstrapping) experiments that provide statistics on the degree to which the recent decline is unusual in terms of its own variability. Specifically, we randomly resample the full historical period (119 years; 1900-2018) area-averaged cool-season rainfall 10000 times and each time the mean rainfall difference between the most recent 22 years period and the mean rainfall over the first six decades is computed. The relative frequency distributions of these 10000 samples of rainfall differences are computed (Fig. 5a). The results suggest that the recent decline in cool-season rainfall is very unusual (over $95 \%$ significance) in terms of its own variability. It also indicates that the chance of such occurrence of low rainfall in recent decades due to natural internal climate variability alone is less than $2 \%$. This suggests that at least some of the drying is due to external forcing, be that human-induced (e.g., rising levels of atmospheric greenhouse gases, aerosol emissions, or the Antarctic ozone hole) or natural (solar variability or tropical volcanic eruptions). This issue is further explored below and in section $3 \mathrm{f}$

An additional way of estimating the extent to which human-induced forcing has caused a change is to examine climate model simulations with and without human-induced forcing included in the simulations. The difference between the two simulations can then be used to quantify the impact of human-induced forcing on the climate system, including Victorian rainfall changes.

\section{c. Evaluation of CMIP5 models over Victoria}

To use climate models to assess the contribution of external forcing to the recent cool-season drying, we must first evaluate if they are fit for purpose. Many studies have evaluated the skill of climate models in simulating a wide range of climate features by comparing their outputs with a set of high-quality observations both internationally (e.g., as part of the IPCC AR5 process), nationally (e.g., CSIRO and Bureau of Meteorology 2015), and regionally (e.g., CSIRO 2010, 2012; Hope et al. 2017). However, regional evaluation of CMIP5 models for Victoria is limited (e.g., Bhend and Whetton 2015; Grose et al. 2015b,a; Moise et al. 2015; Timbal et al. 2015).

Figure 6 shows the mean annual cycle of rainfall over Victoria for the period 1900-2018 as observed (black 

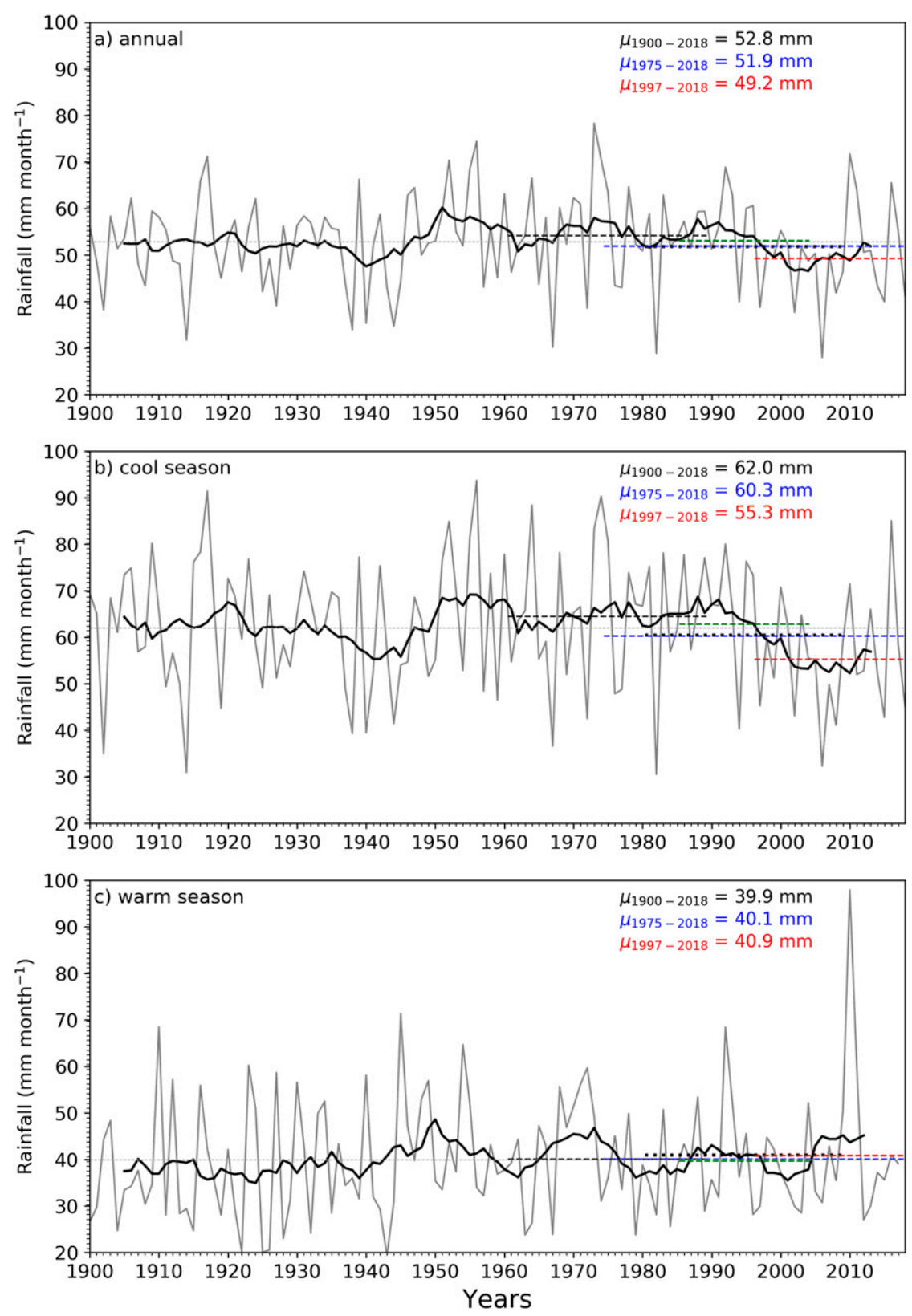

FIG. 3. Time series of the observed mean rainfall (gray) and the 11-yr running mean (black), both in mm month ${ }^{-1}$, over Victoria, Australia: (a) annual, (b) cool season, and (c) warm season. The horizontal black dashed and dotted lines represent the rainfall averages corresponding to the WMO baseline periods 1961-90 and 1981-2010. Similarly, rainfall averages for the CSIRO/ BoM baseline period 1986-2005 and DELWP-adopted baseline period 1975-present are shown by green and blue dashed lines, while that for the post-1997 baseline period is shown by a red dashed line. Average values for the long-term climatology (1900-2018), the DELWP baseline period, and the recent period since the beginning of the Millennium Drought in 1997 are shown in the top-right corner of each panel.

line) and simulated in 24 CMIP5 models under the histALL plus RCP8.5 scenario (dark gray lines). The mean annual cycle for the piCTL runs using 500 years of data from the above models is also shown in light gray lines. Consistent with the VicCI results, which used 19862005 as a baseline, we found that the majority of CMIP5 models simulate the timing of seasonal rainfall pattern adequately, but with some exceptions. For example, a few 


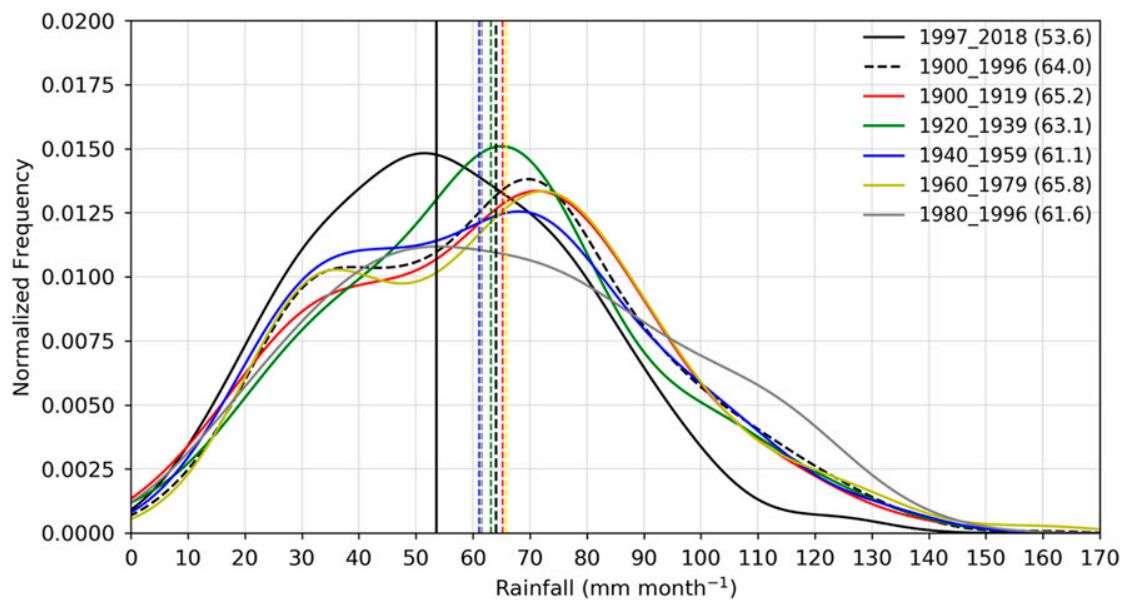

FIG. 4. Relative frequency distributions of Victoria-averaged cool-season monthly mean rainfall for different 20-yr blocks from 1900-19 to 2000 (see legend) are shown by colored lines. The same distributions, but for the 1997-2018 period (start of Millennium Drought to nearpresent) and for the pre-Millennium Drought period 7(1900-96) are shown in solid and dashed black lines, respectively. The vertical lines represent the median values of the distributions and are shown in the parentheses in the legend. The Australian Water Availability Project (AWAP; Jones et al. 2009) monthly rainfall data regridded at $1.5^{\circ} \times 1.5^{\circ}$ are used.

models ( 3 out of 24 ) show a reversed annual cycle (i.e., a summer peak in rainfall for Victoria) and there exists large intermodel spread. Nevertheless, the multimodel ensemble mean exhibits a seasonal evolution similar to its observed counterpart. However, the multimodel ensemble mean tends to underestimate the observed rainfall in all seasons except summer. In addition, the peak-to-peak amplitude of multimodel mean is approximately $25 \mathrm{~mm}$ month ${ }^{-1}$ while the same for the observation is around $35 \mathrm{~mm}$ month $^{-1}$. Figure $6 \mathrm{~b}$ shows that this is due to underestimation of rainfall during the cool season but overestimation during the warm season. Furthermore, the models tend to slightly delay (by a month) the start of rainy season over Victoria compared to the observation. Our analysis shows that the annual cycle of rainfall under historical conditions is slightly drier in the cool season and wetter in the warm season compared with preindustrial runs of the same models. This indicates that the dry bias and warming bias (not shown) evident in the historical runs are at least partially linked.

Note that the magnitude of cool-season drying in the historical runs with respect to piCTL runs is small compared with the observed decline. Models simulations are further evaluated by comparing the relative frequency of randomized differences for models with the observed equivalent as shown in Figs. 5a-c (cf. black and gray distributions). It shows that the observed distribution has a greater spread than the model distribution. This can arise if the models tend to underestimate internal variability and/or the models underestimate the externally forced drying. We will examine these issues in more detail below in section 3f. Given the limitations of current models, we also evaluated results based on the best-performing models (poor performance score less than or equal to 2 in the last column of Table 1). The score represents the number of times a model scored low on various skill metrics used for model evaluation (Timbal et al. 2016; CSIRO and Bureau of Meteorology 2015). These results are discussed in section $3 d$.

\section{d. Simulation of past, present, and future rainfall changes}

To better understand whether the recent dry decades are consistent with the expectations of climate change under greenhouse gas forcing, we analyzed changes in rainfall in 20-yr blocks from 1900-19 to 2100 under different RCP scenarios relative to 500-yr-long piCTL simulations. Figure 7 shows the percentage changes in rainfall for these periods as well as the possible range of multidecadal changes that can arise due to internal variability alone. According to models, the net externally forced signal is very small during the twentieth century, and there is very little agreement among models on the sign of the change (ranges from $56 \%$ to $75 \%$ ). In addition, the multimodel median (MMM) values are close to zero with interquartile ranges being mostly within one standard deviation of the piCTL distribution's mean. However, the impact of external forcing is very clear by the end of twenty-first century under all three RCP scenarios. The results also indicate that the impact of emission reduction 

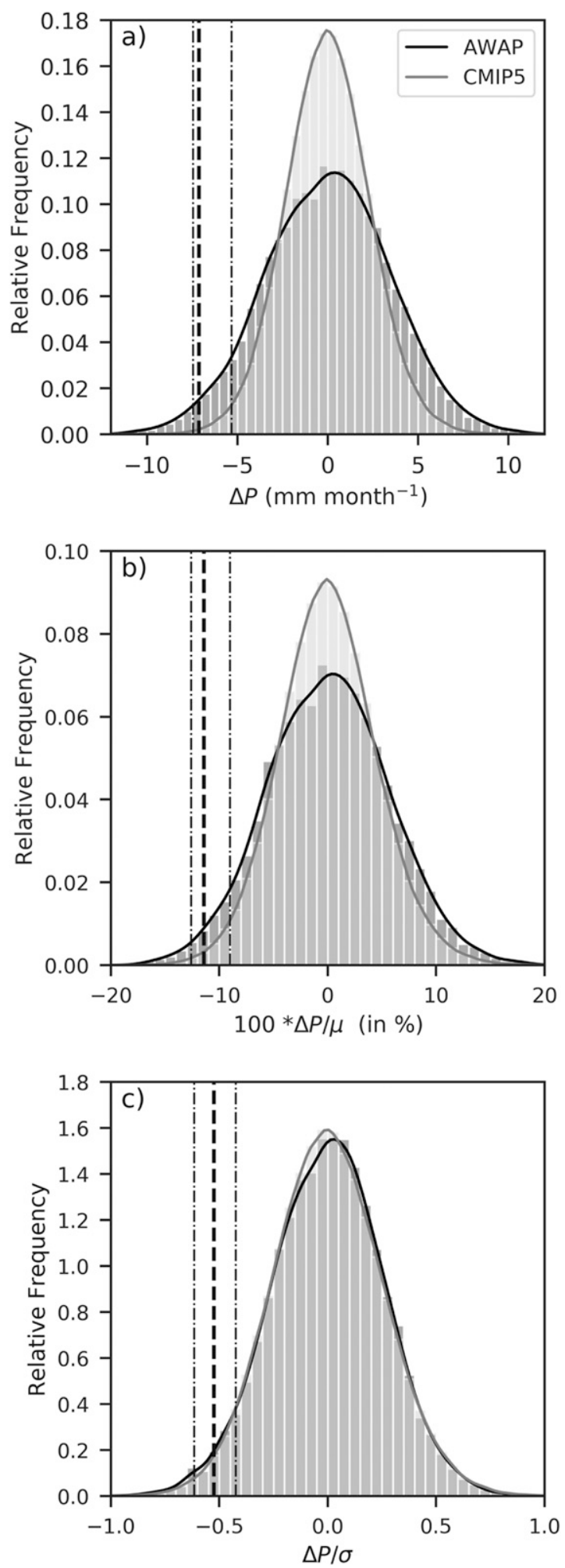

FIG. 5. Relative frequency distributions of the area-averaged Victorian cool-season (a) mean rainfall change $(\Delta P)$, (b) percentage change $(100 \times \Delta P / \mu)$, and (c) standardized change $(\Delta P / \sigma)$ between the recent 22 -yr period and the first 60 -yr period calculated by random resampling of the full historical period (119 years; 1900-2018) 10000
(RCP8.5 vs RCP2.6) is clear from the mid-twenty-first century in terms of median change; the MMM changes are similar under all the three RCP scenarios prior to 2060.

By late twenty-first century, the MMM percentage change in rainfall is $-16 \%$ with an interquartile range (IQR) of approximately $-29 \%$ to $-9 \%$ under RCP8.5 forcing. The lowest-emission scenario (RCP2.6) projects a decline of $-7 \%$ with an IQR between $-9 \%$ and $-5 \%$, while the projected decline for the intermediate-emission scenario (RCP4.5) is $-9 \%$ for with an IQR of $-13 \%$ to $-6 \%$. The MMM change under RCP8.5 is almost 4 times the standard deviation of piCTL variability, which is well beyond the modeled range of internal climate variability in the piCTL simulations. The externally forced change in rainfall after year 2060 under RCP8.5 implies that substantial drying over Victoria is inevitable because internal variability is, by comparison, far too weak to offset it. Of course, there is approximately a $50 \%$ chance that internal variability will actually exacerbate the externally forced drying. The MMM drying during near future periods (e.g., 2010-29 and 2018-37), on the other hand, is smaller than this. The MMM value for 2010-29 shows a change in rainfall of $-4 \%$ (IQR: $-8 \%$ to $-2 \%$ ) whereas for the near future (2018-37) the MMM drying increases slightly to approximately $-5 \%$ (IQR: $-8 \%$ to $-3 \%$ ). For $2018-37$, we estimate that there is a $12 \%$ chance that externally forced drying averaged over this period could be completely masked by internal variability. Equivalently there is an $88 \%$ chance that the $2018-37$ period will be drier than the preindustrial average. Confidence in these numbers are lowered as the models tend to underestimate the magnitude of internal variability (see section $3 \mathrm{f}$ and discussion for details).

The decline in rainfall is evident from the early twenty-first century (e.g., 2010-29) in the sense that during this period over $90 \%$ of models agree on the sign of the MMM change (i.e., negative) under all three RCP scenarios. The MMM value for the more recent decadal period (1997-2018) is approximately $-2 \%$ with IQR of $-4 \%$ and $+1 \%$, which suggests that external forcing

\footnotetext{
times and computing the difference each time. Symbols $\mu$ and $\sigma$ represent the mean and interannual standard deviation of the data during the first 60 years. The observed (model) histogram is shown in dark (light) gray bars with the fitted Gaussian kernel distribution overlaid by a black (gray) line. Bin sizes are respectively $0.5 \mathrm{~mm}$ month $^{-1}, 1 \%$, and $0.05 \%$ for change, percentage change, and standardized change. Black dashed and dotted vertical lines from left to right represent $1 \%$ and $5 \%$ probability of exceedance based on the observed distribution. Dark dashed vertical lines denote the observed difference between the means of the recent 22-yr period (1997-2018) and the first 60-yr period (1900-59).
} 

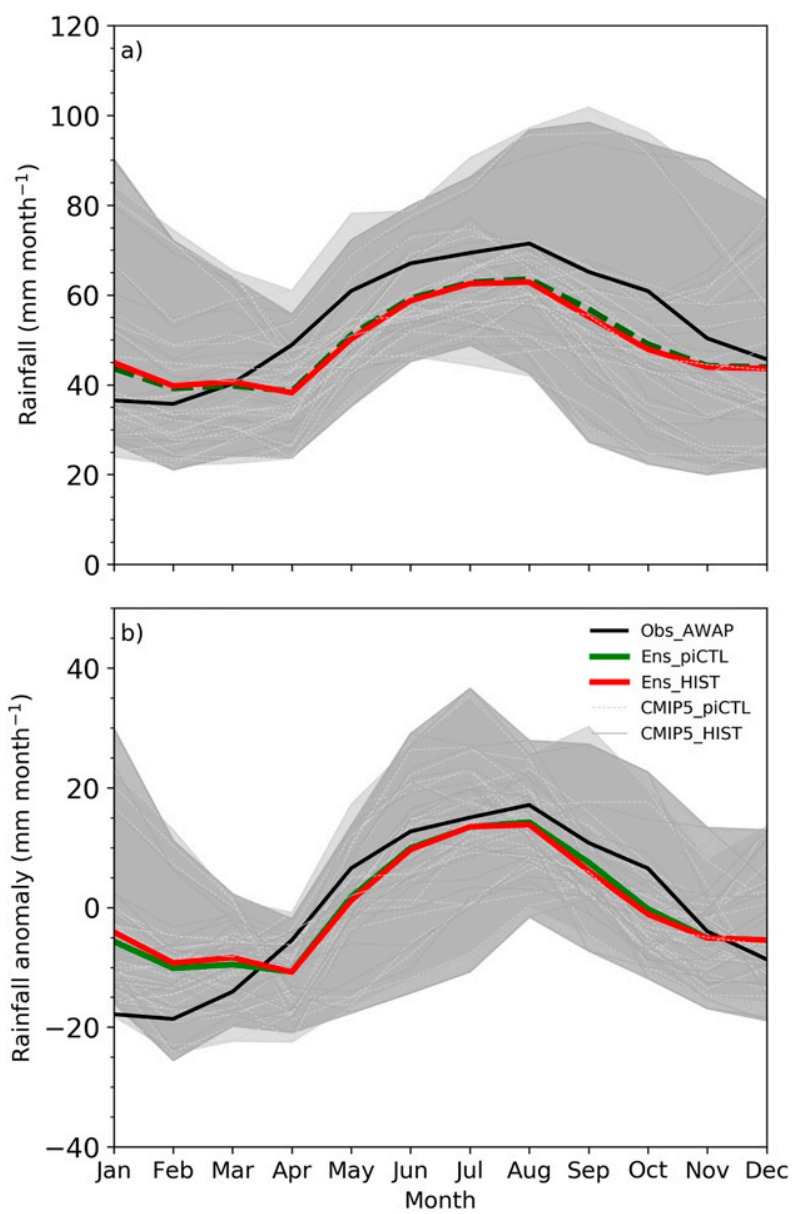

FIG. 6. CMIP5-simulated (a) mean annual cycle of rainfall using the 1900-2018 period and (b) the corresponding amplitudes relative to the long-term annual mean climatology. Observations based on AWAP are shown by a black line. The multimodel ensemble mean for the same period under histALL simulation patched with RCP8.5 (HIST/RCP8.5) scenario is shown by a red line and the ensemble mean of piCTL models with at least 500 years of simulation is shown by a green line. Individual HIST/RCP 8.5 and piCTL models as listed in Table 1 are shown in dark and light gray colors. Shaded areas indicate the minimum and maximum values of HIST/RCP 8.5 models (dark gray) and piCTL models (light gray), respectively.

only makes a small contribution to the observed decline. Estimates of the other descriptive statistics for each 20 -yr block using the numbers of models available under three RCP scenarios are given in Table 2.

The conclusions remain the same as described above even if attention is restricted to the best-performing models, with performance based on the metrics listed in Table 1. For example, the MMM value using the 18 best models under RCP8.5 forcing exhibits a $20 \%$ decline toward the end of the twenty-first century (not shown), which is slightly higher than the drying estimated using all 24 models (i.e., $-16 \%$ ). However, there exists no difference in the interquartile range ( $-29 \%$ to $-9 \%)$. Similarly, we
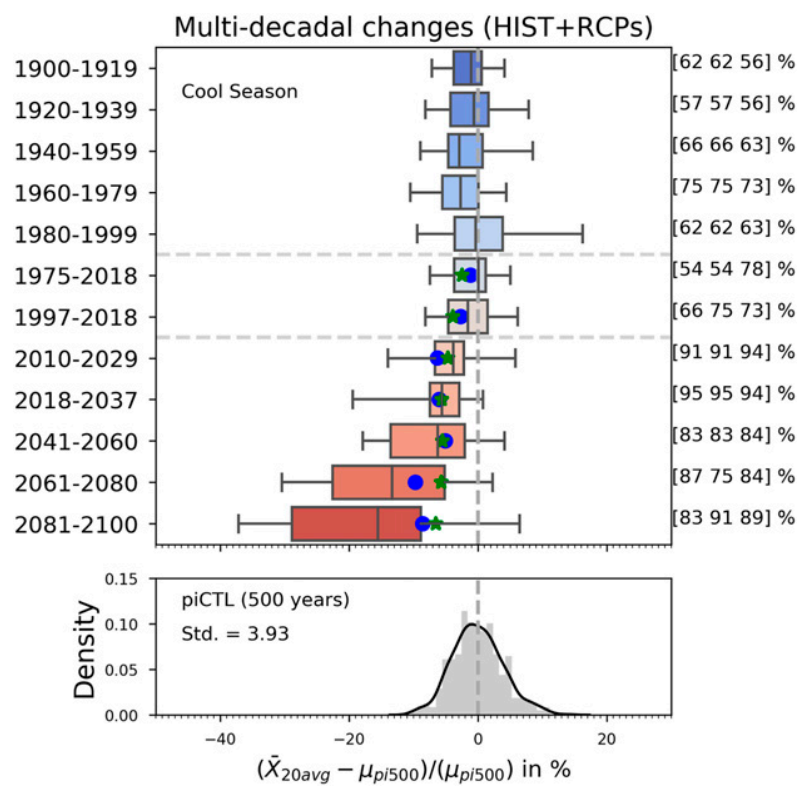

FIG. 7. (top) The percentage changes in cool-season mean rainfall in 20-yr blocks from 1900-19 to 2081-2100 (shown on the left side of the $y$ axis) under historical and three RCPs scenarios. Changes are calculated relative to 500 years of piCTL runs. The same 24 models are used for the piCTL, historical, and RCP8.5 simulations (see Table 1). For each 20 -yr block, the distribution of changes in 24 models under RCP8.5 are represented as box-and-whisker plots for each 20 -yr period. The vertical line in the box indicates the median, the shaded box represents the 25th to 75th percentiles, and the whiskers indicate the minimum and the maximum values based on 24 CMIP5 models. The median values for RCP4.5 and RCP2.6 scenarios are overlaid on the boxplots as blue circles and green stars, respectively. The fractions of models that exhibit the same sign as the median are shown on the right side of the $y$ axis in order for RCP2.6, RCP4.5, and RCP8.5. (bottom) The range of piCTLmodeled internal climate variability computed as the relative frequency of changes in mean rainfall in 20 -yr blocks in 500 years of piCTL runs.

did not find any substantial difference between the results using the best models only and all available models for the recent (1997-2018) and near-future (2018-37) periods.

\section{e. Role of greenhouse gases (GHGs)and natural processes}

In this section, we examine three different historical runs-histALL, histGHG, and histNAT-to quantify the extent to which human-induced forcing has caused an observed change in Victorian rainfall. Unfortunately, the simulations of rainfall under these forcings are only available to the year 2005. The time series shown in Fig. 8 represents the percentage changes in rainfall relative to the mean of 500 years of piCTL simulations. These are smoothed using 20-yr running mean to remove the year-to-year variability. Therefore, the results shown in Fig. 8 are more representative until the 1995 (i.e., average of 1986-2005). Despite this, the result shows that 10 out of 13 models simulate decrease in 


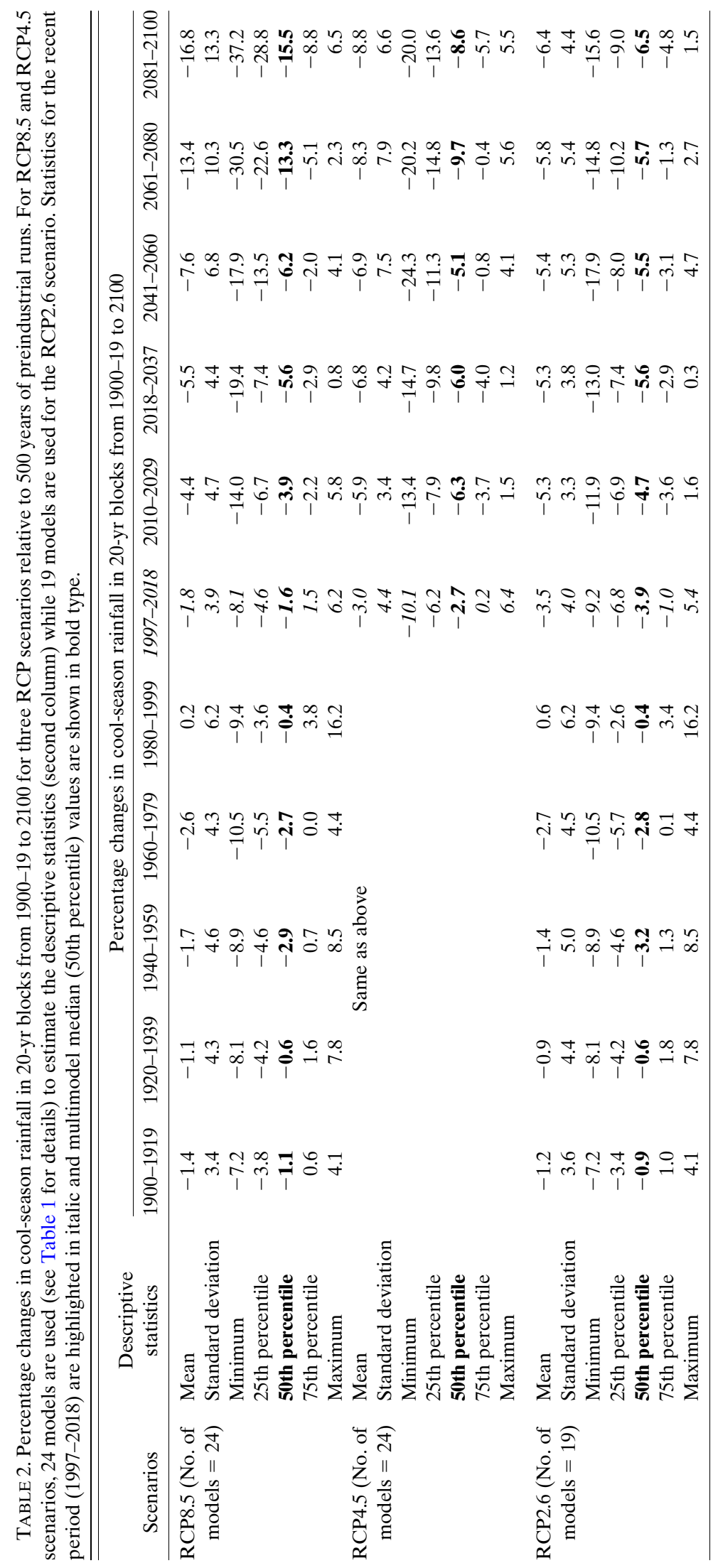



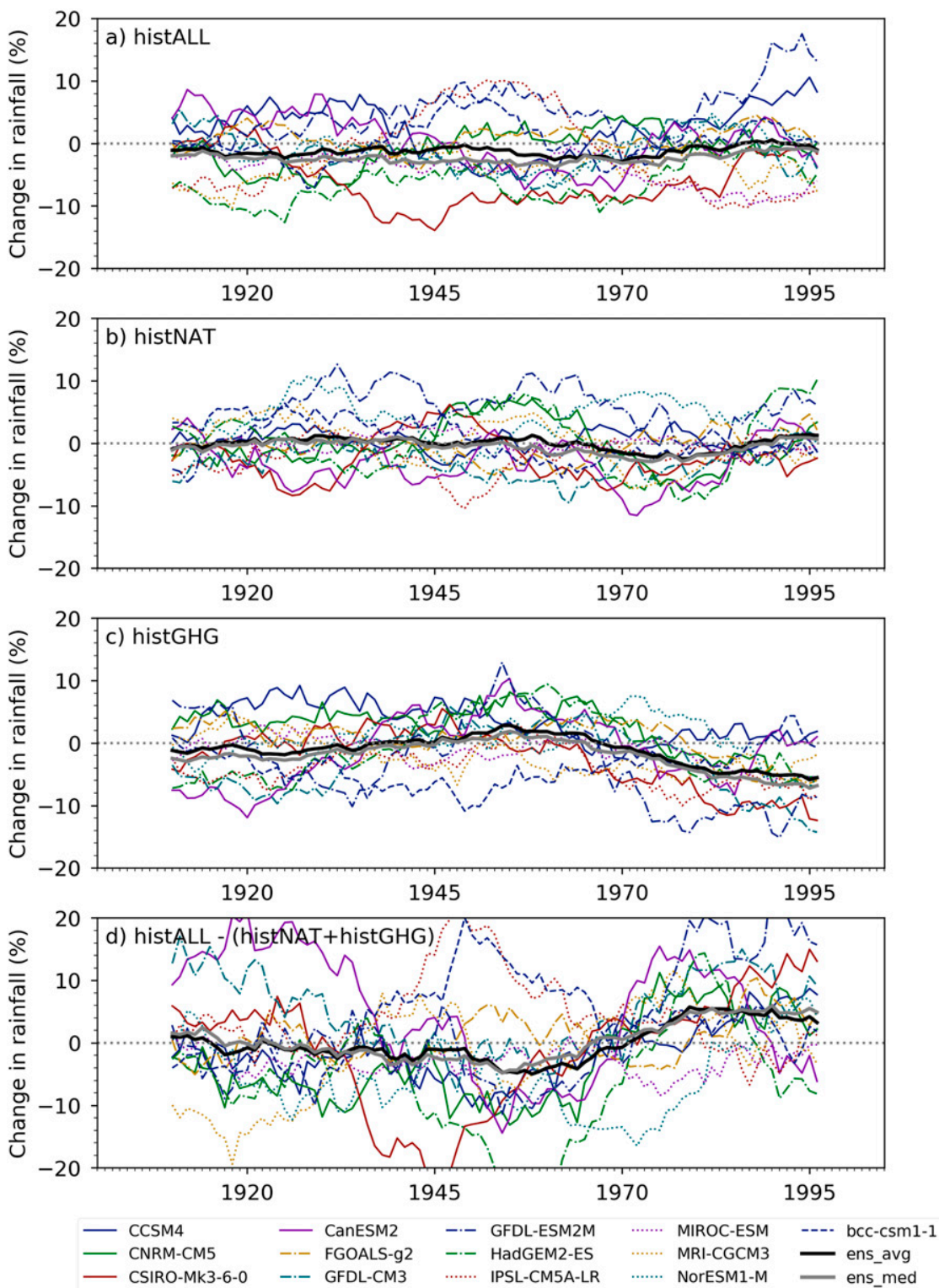

FIG. 8. Time series of percentage change in cool-season multidecadal $(20 \mathrm{yr})$ rainfall in historical model simulations with (a) all, (b) natural-only, (c) GHG-only, and (d) non-GHG anthropogenic forcing. Note that (d) represents the rainfall response from historical with the impact from both GHGs and natural external forcing subtracted. Responses are assumed to be linear. Changes are relative to 500 years of piCTL runs. Only 13 models were available at the time study with all three historical forcings (see Table 1).

rainfall post-1970 under histGHG simulations. This suggests that the increased concentration of GHGs emission generally leads to a drier climate over Victoria. On the contrary, when the models are forced with the histNAT (e.g., volcanoes, solar variability) forcings, no robust trend exists. It is likely that the drying caused by greenhouse gases in the late twentieth century could have been disguised by natural processes, model internal variability, and aerosols. To test this, we computed the rainfall response from histALL with the impact from both histGHG and histNAT external forcing subtracted (Fig. 8d). It shows an MMM increase toward the end of the twentieth century. This might merely reflect sampling error arising from internal variability. On the other hand, perhaps non-GHG external forcing (e.g., sulfate aerosols) is partially offsetting the GHG drying, which is evidenced in 9 out of 13 models. As a result, the histALL forcing simulations do not show any significant decrease in rainfall toward the end of the 
TABLE 3. Contribution of anthropogenic forcing to observed drying for the period 1997-2018 relative to 1900-59. Change ( $\Delta$ ), percentage change $(100 \times \Delta / \mu)$, and standardized changes relative to internal standard deviation $(\Delta / \sigma)$ and decadal standard deviation $\left(\Delta / \sigma_{d}\right)$ are considered. Here $\Delta$ is the difference in Victorian-averaged mean rainfall between 1997-2018 and 1900-2018, $\mu$ is the Victorianaveraged rainfall over the 1900-59 period, and $\sigma$ and $\sigma_{d}$ are respectively the interannual and interdecadal standard deviation of Victorian averaged rainfall over the same period. Observed change ( $\triangle \mathrm{OBS})$ is shown in column 2. The multimodel median (MMM) values of the simulated changes for three different RCPs are shown in columns 3-5 along with the interquartile ranges (shown in parentheses in italic type). The "weighted mean" change is the average of $\triangle \mathrm{MMM}$ for all three RCPs, weighted by the number of models (i.e., 40, 38, and 27, respectively, as shown in parentheses). The relative contribution of anthropogenic forcing to the observed drying is shown in the last column as a percentage in bold type for MMM, together with IQRs in parentheses in italic and bold type.

\begin{tabular}{|c|c|c|c|c|c|c|}
\hline \multirow[b]{2}{*}{$\begin{array}{c}\text { Standardization } \\
\text { methods }\end{array}$} & \multirow[b]{2}{*}{$\Delta \mathrm{OBS}$} & \multicolumn{3}{|c|}{ MMM and IQR } & \multirow[b]{2}{*}{$\begin{array}{c}\text { Weighted } \\
\text { mean }(\Delta \mathrm{MMM})\end{array}$} & \multirow{2}{*}{$\begin{array}{c}\text { Percentage } \\
\text { contribution } \\
(100 \times \\
\Delta \mathrm{MMM} / \\
\Delta \mathrm{OBS})\end{array}$} \\
\hline & & RCP8.5 (40) & RCP4.5 (38) & RCP2.6 (27) & & \\
\hline$\Delta$ & $\begin{array}{l}-7.8 \mathrm{~mm} \\
\text { month }^{-1}\end{array}$ & $-0.7(-2.6,1.0)$ & $-2(-2.8,-0.3)$ & $-1.6(-3.0,0.1)$ & $-1.35(-2.8,0.3)$ & $17(36,-4)$ \\
\hline $100 \times \Delta / \mu$ & $-12 \%$ & $-1.3(-4.4,1.7)$ & $-3.6(-5.3,-0.6)$ & $-3.2(-5.3,0.2)$ & $-2.5(-5,0.5)$ & $20(40,-4)$ \\
\hline$\Delta / \sigma$ & -0.6 & $-0.07(-0.23,0.1)$ & $-0.2(-0.28,-0.02)$ & $-0.14(-0.33,0)$ & $-0.14(-0.27,0.03)$ & $23(45,-6)$ \\
\hline$\Delta / \sigma_{d}$ & -2.05 & $-0.28(-0.83,0.3)$ & $-0.76(-1.3,-0.09)$ & $-0.63(-1.4,0)$ & $-0.55(-1.14,-0.15)$ & $26(55,-5)$ \\
\hline
\end{tabular}

twentieth century. Further research is needed to clarify the relative importance and impact of the various individual forcings to the observed changes.

\section{f. Past changes in Victorian rainfall}

The observed decline in rainfall for 1997-2018 is more than 2 times the interdecadal variability of 1900-2018, which is extremely large (Table 3 ). To examine how unusual the observed and simulated changes in rainfall during recent decades are relative to the modeled internal variability, we computed the percentage changes in mean rainfall of the recent 22-yr period (1997-2018) relative to the first 60-yr period (1900-59) for all the models under historical forcing and the three RCP scenarios. We computed the same statistic (i.e., percentage change from the first six decades to a subsequent 22-yr period) for the piCTL models with at least 200 years of simulations. For each piCTL model, we repeated this 1000 times and each time the percentage difference between the average of the last 22 years and the average of the first six decades is computed. This is done to remain consistent with Fig. 5 in which only 119 years of data are used. This provides us with a sample of 35000 values (35 models $\times 1000$ ) of percentage rainfall changes due to internal climate variability alone. This is used to estimate the range of modeled internal multidecadal climate variability as shown in the lower panel of Fig. 9. The results show that the magnitude of the observed drying over 1997-2018 period $(-12 \%)$ is unusually large relative to internally generated multidecadal variability in the models. An alternative expression, preferred by a reviewer, is that the differences are statistically significant at the $1 \%$ significance level. In fact, we estimate there is less than a $1 \%$ chance that the observed drying could occur from internal variability alone. Note that in estimating the magnitude of multidecadal variability we assumed that the variability is well represented as a white noise process. If the variability is not a white noise, then it is possible that we are underestimating the magnitude.

We also found that only one model (i.e., IPSL-CM5B-LR) under either RCP8.5 and RCP4.5 exhibits drying as great as the observed drying. We estimated the magnitude of the externally forced drying in models by averaging the median values of all three RCPs, but each scenario is weighted by the number of models used under that scenario (see Table 3 for number of models under each scenario and corresponding median values). We did the same for the IQR values of three RCPs and found that the externally forced median drying is only $-2.5 \%$ with an IQR around -5 to $+0.5 \%$. This suggests that the $12 \%$ decline has two components, one of $2.5 \%$ from anthropogenic forcing and another from internal variability of $9.5 \%$. The percentage contribution of anthropogenic forcing, taking models as face value, is $20 \%$ (i.e., $100 \times$ $2.5 \% / 12 \%)$. However, there is large uncertainty. The IQR range, for example, is $40 \%$ to $-4 \%$ (Table 3 ). Given that the model simulations underestimate the observed rainfall variability (see below), the above estimates of the external forcing contribution may be underestimated.

A $20 \%$ decline in the mean increases the likelihood of experiencing drying as large as the observed drying (from 0.0033 to 0.0148 , a fivefold increase). This estimate is based on adjustment of the relative frequency distribution of preindustrial model output (Fig. 9) to reflect the decline in the mean. The likelihood 

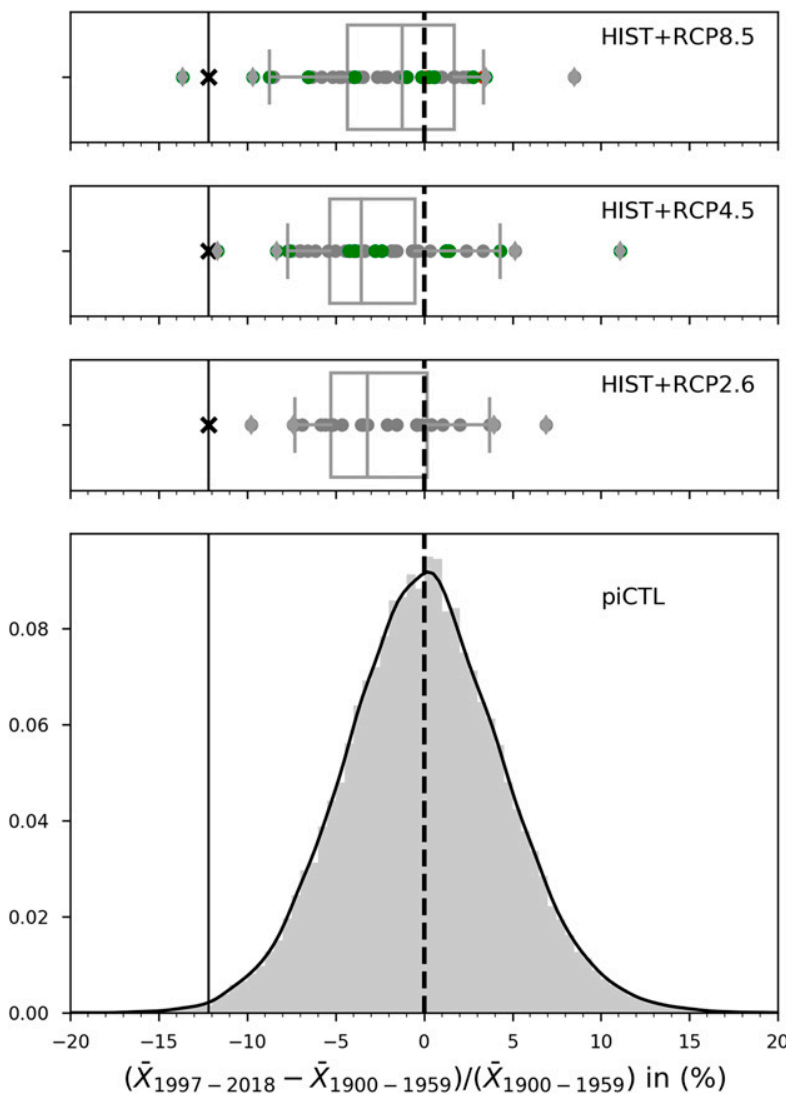

FIG. 9. Percentage changes in rainfall of the recent 22-yr (1997-2018) period relative to first 60-yr (1900-59) period in CMIP5 models under (top three panels) historical and three RCP scenarios as well (bottom) as the piCTL runs. Boxplots of change in rainfall are based on histALL simulations extended with 40 models under RCP8.5 in the top panel, 38 models under RCP4.5 in the second panel, and 27 models under RCP2.6 scenarios in the third panel. The vertical line in the box indicates the median, the box represents the interquartile range (IQR: 25 th to 75 th percentiles), and the whiskers indicate the 5th to 95th percentiles. The 27 CMIP5 models that provide rainfall simulations under all three RCP scenarios are shown by gray circles. The models that are not in RCP2.6 but are in RCP8.5 and RCP4.5 (total of 11) are shown by green circles. Similarly, the models (total of 2) that have simulations under RCP8.5 only, not in other RCP scenarios, are shown by red circles. The bottom panel is as in bottom panel of Fig. 5, but using 35 CMIP models with at least 200 years of piCTL simulation. The relative frequency distribution shown in the bottom panel is computed using 35000 samples of rainfall change from 35 piCTL models, each randomized 1000 times to compute the change in mean rainfall of the recent 22-yr period from the first six decades. The vertical dashed line indicates no change in average rainfall between the most recent 22 years and the first 60 years. The observed percentage change is indicated using crosses and the thin vertical solid line.

will be larger if the models underestimate internal variability.

The conclusions are very similar if the data are standardized by the standard deviation of variability over the first 60 years (see Table 3 for details). With standardized data, a larger number of models ( 3 to 5 , depending on the scenario) simulate dry conditions similar to the observed difference (not shown) and the percentage contribution of anthropogenic forcing for the standardized change is slightly larger (i.e., $23 \%$ ). The fact that more models are able to simulate standardized drying suggests that the models might underestimate variability. This would also help to explain why the contribution of anthropogenic forcing to the standardized decline in rainfall is larger than the contribution to the percentage change. We will examine the ability of models to simulate variability below.

It is of interest to compare the magnitude of the projected changes with changes that have already been observed as in Fig. 10, which shows observed rainfall changes during the World War II and Millennium Droughts and during the last 22 years (i.e., 1997-2018), together with simulated changes for the twentieth and twenty-first centuries. The plot illustrates several important points. For example, the MMM projected drying in the late twentyfirst century under RCP8.5 (i.e., $12 \%$ relative to 1900-59) is not as large as the drying that was observed during the MD (15.7\%). The fact that the simulated drying during all periods from 1900 to 2100 is lower than the drying that was observed during the MD further illustrates that-according to the models - the MD drying was dominated by internal variability, and not external forcing.

On the other hand, the projected drying in the late twenty-first century under RCP8.5 is larger than the observed WWII drying (9\%) and approximately the same as the drying observed during the last 22 years $(12.1 \%)$. This illustrates that global warming will significantly increase the risk of events like the WWII and recent droughts. As expected, the late-twenty-first-century MMM drying is smaller under RCP4.5 relative to RCP8.5. However, it is still similar in magnitude to the WWII drought.

Note that these MMM values are estimates of the impact of external forcing on rainfall. What rainfall Victoria receives will also be a function of internal variability. However, the externally forced drying under RCP8.5 is so large that internal variability will-again according to the models-either exacerbate drying to levels that rival or exceed the MD drying, or they might offset the externally forced drying to WWII drought levels. Offsets larger than this appear unlikely.

In summary, the results imply that the recent decline in rainfall is very unusual and more than $95 \%$ of models underestimate the magnitude of the observed drying. The underestimation of the changes in rainfall by the models can arise, in principle, from one or more of four nonmutually exclusive reasons [as per framework outlined by Kociuba and Power (2015) and Power et al. (2017)]:

- Observational error. If this contributed at all, we assume it would be a very minor contribution as we used high-quality gridded data produced by the Australian Bureau of Meteorology. 


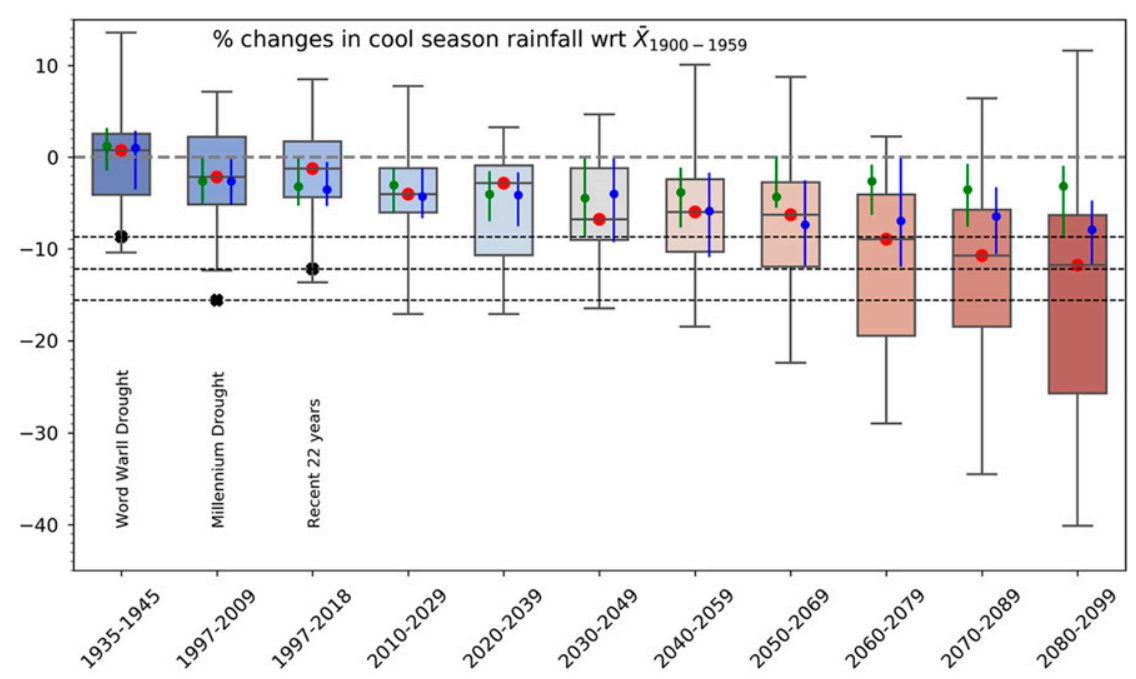

FIG. 10. Simulated percentage changes in cool-season rainfall compared with observed changes during the World War II and Millennium Droughts, and the recent period 1997-2018, all relative to 1900-59. As in Fig. 7, the distributions of changes in 24 models under RCP8.5 are represented as box-and-whisker plots for each 20 -yr period. The horizontal line in the box indicates the median, the shaded box represents the interquartile range (IQR: 25 th to 75 th percentiles), and the whiskers indicate the minimum and the maximum values based on 24 CMIP5 models. The median values for RCP4.5 and RCP2.6 scenarios are overlaid on the boxplots by blue and green circles, with corresponding IQRs represented by the blue and green vertical lines, respectively.

- The real world exhibited a very unusual and extreme internally generated event. In section 3 a we found that the recent observed drying is very unusual in terms of both observed variability and modeled internal variability. However, we do not know for sure what caused the observed change: it could be dominated by a large forced response or by an unusually large internally driven, natural event.

- Models underestimate the forced response. This is a possibility we cannot exclude. This can arise because the models are not sensitive enough to greenhouse gas forcing, or because the forcing (e.g., to sulfate aerosols) applied to model is imperfect, and this leads to an underestimate of the drying.

- Model variability is too weak. Figure 11 illustrates that the models do indeed appear to underestimate both interannual and decadal variability. However, even if standardized changes are examined, the models still tend to underestimate the observed change. So, the weaker than observed variability contributes to the difficulty, but it is not the sole cause.

\section{Summary and discussion}

The cool season (e.g., April to October) in Victoria in southeast Australia is important for many crops and for replenishing reservoirs. Rainfall over Victoria during the cool season has been approximately $12 \%$ below the twentieth-century average since the beginning of the MD in 1997, which is very unusual by historical standards $(p$ value $<0.05)$. This contrasts with the warm season (November to March), which exhibits virtually no change at all in rainfall over the same period.

We analyzed 24 CMIP5 global climate models forced under preindustrial historical conditions, as well as three scenarios for the twenty-first century: RCP2.6, RCP4.5, and RCP8.5. We also examined historical runs in which greenhouse gas (GHG) increases and natural external forcing were applied separately. Our analysis shows that while GHGs appear to have contributed to drying in the late twentieth century, the effect in models on drying during the twentieth century has been offset by other processes. These cannot be unambiguously identified here, but there is a suggestion of increased rainfall either from volcanic or solar changes, sampling issues, or from non-GHG anthropogenic forcing (e.g., sulfate aerosols). The results also show that while 1997-2018 average rainfall is below the preindustrial average in two-thirds or more of models under the three scenarios, the magnitude of the externally forced median drying is only $-2.5 \%$ in all three scenarios (with an interquartile range of approximately -5 to $+0.5 \%$ ). The model results suggest that external forcing contributed only $20 \%$ (interquartile range $40 \%$ to $-4 \%$ ) of the drying observed in 1997-2018, relative to 1900-59. Together these results 


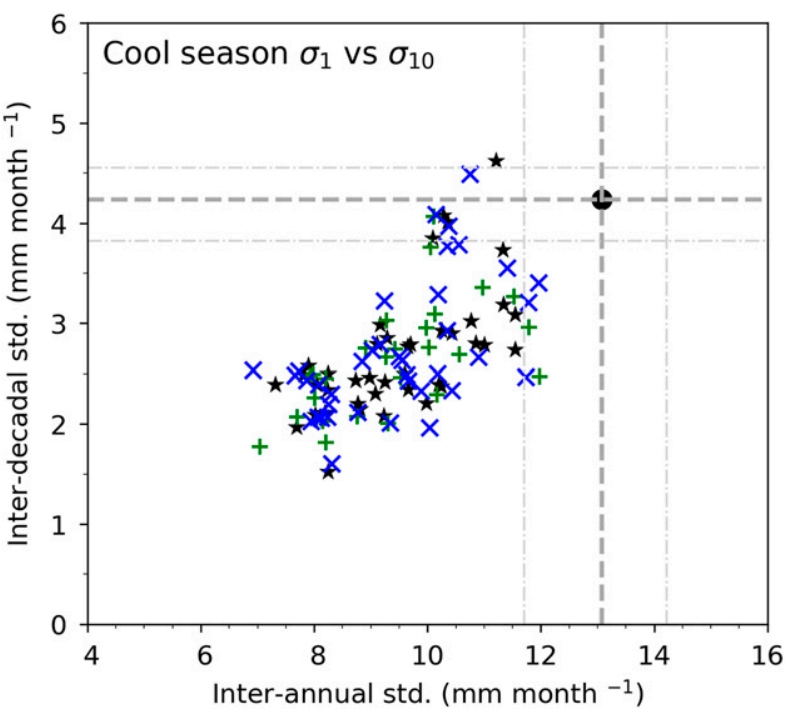

FIG. 11. Comparison between the model-simulated and the observed cool-season rainfall standard deviations (std), both in $\mathrm{mm} \mathrm{month}^{-1}$, for the period 1900-2018. Interannual and decadal standard deviations are shown along the $x$ and $y$ axes, respectively. The crossing point of the dashed dark gray lines, marked with a black filled circle, represents the observation, and the light gray lines represent the 5\% and 95\% confidence intervals of the standard deviation using bootstrapping. The histALL simulations extended with the RCP8.5, RCP4.5, and RCP2.6 scenarios are respectively shown in black stars, blue crosses, and green plus symbols.

suggest that the observed drying was dominated by natural internal rainfall variability. Given that the models poorly simulate the observed variability, the above estimates of the external forcing contribution may be underestimated. Nevertheless, over southwestern Australia, Delworth and Zeng (2014) found that a possible underestimation of decadal variability by their model did not alter their primary conclusions. This is also seen in this study when the change is scaled by decadal variability, the contribution of external forcing increases slightly to $26 \%$ with an interquartile range of $55 \%$ to $-5 \%$.

In contrast, Hoerling et al. (2010) found that the vast majority of CMIP3 models show a positive trend over the 1977-2006 period, whereas a decline in annual rainfall over southeast Australia was observed. Their results showed that neither SST nor anthropogenic forcing contributed to the observed decline. Hoerling et al. (2010) suggested that the observed decrease they examined could be reconciled with a bout of strong atmospheric internal variability representing a 1.4 standardized departure to match the amplitude of the observed 30-yr drying in annual rainfall. Our analysis showed that a 2.05 standardized departure is required to match the observed recent 22-yr decline in cool-season rainfall. The differences between Hoerling et al. (2010) and this study are expected as we have analyzed the cool season Victorianaverage rainfall for the recent 22-yr period (1997-2018) as opposed to annual rainfall for an earlier 30-yr period (i.e., 1977-2006) over a larger southeast Australian region. Furthermore, we examined CMIP5 models-which show an overall improvement over Australia compared with CMIP3 models (CSIRO and Bureau of Meteorology 2015; Moise et al. 2015). Finally, Delworth and Zeng (2014) also found that the observed changes during autumn and winter for the period 1981-2012 relative to the 1911-70 period over southeastern Australia were unusual, although not clearly distinguishable from internal variability.

While the multimodel median (MMM) is below the long-term (i.e., 500 years) piCTL average from 19972018 onward, the externally forced drying only becomes clear during 2010-29, when the proportion of models exhibiting drying increases to over $90 \%$ under all three scenarios. In some models this represents climatic "expulsion" (Power 2014), in which rainfall variability is forced beyond its historical or preindustrial range by anthropogenic forcing. This reflects the increase in the magnitude of the externally forced drying as the twentyfirst century unfolds. For RCP8.5 the change in rainfall is $-4 \%$ (interquartile range is $-8 \%$ to $-2 \%$ ) for $2010-29$ whereas for $2018-37$ the decline is $-5 \%$ (interquartile range of $-8 \%$ to $-3 \%$ ).

The MMM values are very similar for all scenarios prior to 2060 (Table 2). This is in contrast to later periods when the benefits of reducing global GHG emissions in terms of arresting the decline in Victorian rainfall is clear. This indicates that reducing GHG emission as defined in RCP2.6 reduces the likelihood that Victoria will experience drying as strong as in RCP8.5 in the late twenty-first century. The MMM externally forced changes in Victorian rainfall under RCP8.5, RCP4.5, and RCP2.6 are $-13.3 \%,-9.7 \%$, and $-5.7 \%$ for $2061-80$, and $-16 \%,-8.6 \%$, and $-6.5 \%$ for $2080-99$, respectively. These values are consistent with the earlier studies that looked at rainfall changes in the CMIP5 models (e.g., Grose et al. 2015a; Timbal et al. 2015; Hope et al. 2017).

It is important to note that these figures are for the externally forced signal only, and that future Victorian rainfall will be a function of both external forcing and natural processes. Internal variability for example, might over any particular decade end up either temporarily reinforcing or opposing the drying trend due to the externally forced signal. Taking both the magnitude of the externally forced decline and the variability, we estimate that there is a $12 \%$ chance that internal rainfall variability will completely offset the externally forced drying averaged over 2018-37, regardless of scenario. In contrast, the externally forced change under RCP 8.5 by the late twenty-first century is so large (median $=-16 \%$, which is 
approximately 4 times the standard deviation of multidecadal variability) that net drying appears inevitable under RCP8.5.

Confidence in the modeled projections is lowered because models underestimate long-term average Victorian rainfall and the amplitude of the annual cycle of rainfall over Victoria, and the overwhelming majority of models appear to underestimate the magnitude of the observed decline in rainfall. The reasons for this last underestimation-which are not mutually exclusive-were outlined (section 3f) following a framework presented previously (Kociuba and Power 2015; Power et al. 2017): (i) the real world exhibited a very unusual and extremely large natural, internally generated event that dominates the observed drying; (ii) models underestimate the forced response; (iii) model variability is too weak; and/or (iv) observational error, which we do not consider to be a major factor. On the other hand, we showed that some, but not all, of this underestimation appears to arise because most models seem to underestimate multidecadal rainfall variability. This might be linked to an underestimation of the Pacific decadal variability (Power et al. 2017) or the coarse resolution of the CMIP5 models (Chen and Dai 2019). Further clarification of these issues requires additional research. In addition, CMIP5 models are found to exhibit some systematic deficiencies when they are assessed on their ability to simulate key features of atmospheric circulation and modes of climate variability (e.g., STR, jets, atmospheric blocking, baroclinic instability, storm tracks, ENSO, and IOD) and their relationship with Victorian rainfall. For example, many CMIP5 models adequately simulate the broad characteristics (intensification, poleward shift, and seasonal cycle) of the STR under global warming; however, the models underestimate the historical trends in the STR intensity and the magnitude of the correlation coefficient between interannual STR intensity and Victorian rainfall (Grose et al. 2015b, 2017; Timbal et al. 2015). Similarly, CMIP5 models exhibit a substantial bias in modeling the impacts of the trend of the SAM on Victorian rainfall with some models underestimating the winter rainfall decline associated with high SAM and overestimating the increase in summer rainfall (Lim and Hendon 2015; Timbal et al. 2016; Hope et al. 2017). These issues suggest that CMIP5 rainfall projections for Victoria during the cool season in response to the STR and SAM changes may be underestimated, and this lowers confidence in Victorian rainfall projections using the same CMIP5 models. If externally forced drying is underestimated because the response to greenhouse gases is underestimated, then the magnitude of projected changes might also be underestimated. We hope to further investigate these issues in the next generation of-hopefully improved — climate models. Research on the issue raised using downscaled information would be also be useful, particularly for subregional changes near topography.
In closing, it is important to note that the relative importance of causes (i)-(iii) is not known. It would therefore be imprudent to assume that (ii) alone is responsible for the underestimation of the observed drying and to dismiss our estimate of the externally forced contribution to the observed drying in Victorian rainfall (i.e., $20 \%$ with an interquartile range of $40 \%$ to $-4 \%$ ). Further research may well lead to revisions in this estimate, but as it stands, this is the first and best available estimate of the contribution. We hope to revisit these issues using the next generation of climate models and downscaled simulations in future studies.

Acknowledgments. We wish to thank the Victorian Department of Environment, Water and Planning (DELWP) for supporting this research through the Victorian Water and Climate Initiative (VicWaCI) program under joint partnership between the DELWP and Bureau of Meteorology. The authors are grateful to Geoff Steendam, Marty Gent, and Rebecca Lett from DELWP and Pandora Hope, Francois Delage, Hanh Nguyen, and Rob Colman from the Bureau of Meteorology for their helpful suggestions, comments, and encouragement. We also wish to acknowledge that some of the data sets and analysis tools used in this investigation were developed by Francois Delage under the National Environmental Science Program's Earth System and Climate Change Hub. We are grateful to anonymous reviewers for their insightful and constructive comments that improved the quality of the manuscript. We also thank the World Climate Research Programme's Working Group on Coupled Modelling, which is responsible for CMIP, and we thank the climate modeling groups (listed in Table 1 of this paper) for producing and making available their model output. For CMIP the U.S. Department of Energy's Program for Climate Model Diagnosis and Intercomparison provides coordinating support and led development of software infrastructure in partnership with the Global Organization for Earth System Science Portals.

\section{REFERENCES}

Bhend, J., and P. Whetton, 2015: Evaluation of simulated recent climate change in Australia. Aust. Meteor. Oceanogr. J., 65 , 4-18, https://doi.org/10.22499/2.6501.003.

Cai, W., A. Purich, T. Cowan, P. Van Rensch, and E. Weller, 2014: Did climate change-induced rainfall trends contribute to the Australian Millennium Drought? J. Climate, 27, 3145-3168, https://doi.org/10.1175/JCLI-D-13-00322.1.

Chen, D., and A. Dai, 2019: Precipitation characteristics in the Community Atmosphere Model and their dependence on model physics and resolution. J. Adv. Model. Earth Syst., 11, 2352-2374, https://doi.org/10.1029/2018MS001536. 
CSIRO, 2010: Climate variability and change in south-eastern Australia: A synthesis of findings from Phase 1 of the South Eastern Australian Climate Initiative (SEACI). CSIRO, 36 pp., http://www.seaci.org/publications/documents/SEACI-2Reports/ SEACI_Phase2_SynthesisReport.pdf.

_ 2012: Climate and water availability in south-eastern Australia: A synthesis of findings from Phase 2 of the South Eastern Australian Climate Initiative (SEACI). CSIRO, 41 pp., http:// www.seaci.org/publications/documents/SEACI-2Reports/SEACI_ Phase2_SynthesisReport.pdf.

CSIRO and Bureau of Meteorology, 2015: Climate change in Australia information for Australia's natural resource management regions. Climate Change in Australia Tech. Rep., 222 pp., https://www.climatechangeinaustralia.gov.au/media/ccia/2.1.6/ cms_page_media/168/CCIA_2015_NRM_TechnicalReport_ WEB.pdf.

Delworth, T. L., and F. Zeng, 2014: Regional rainfall decline in Australia attributed to anthropogenic greenhouse gases and ozone levels. Nat. Geosci., 7, 583-587, https://doi.org/10.1038/ ngeo2201.

_ and Coauthors, 2012: Simulated climate and climate change in the GFDL CM2.5 high-resolution coupled climate model. J. Climate, 25, 2755-2781, https://doi.org/10.1175/JCLI-D-11-00316.1.

DELWP, 2016a: Guidelines for assessing the impact of climate change on water supplies in Victoria. Department of Environment, Land, Water and Planning, 83 pp., https://water.vic.gov.au/_data/assets/ pdf_file/0014/52331/Guidelines-for-Assessing-the-Impactof-Climate-Change-on-Water-Availability-in-Victoria.pdf.

_ 2016b: Managing extreme water shortage in Victoria: Lessons from the Millennium Drought. Department of Environment, Land, Water and Planning, 124 pp., https://www.water.vic.gov.au/_data/ assets/pdf_file/0029/67529/DELWP-MillenniumDroughtweb-SB.pdf.pdf.

Dey, R., S. C. Lewis, J. M. Arblaster, and N. J. Abram, 2019: A review of past and projected changes in Australia's rainfall. Wiley Interdiscip. Rev.: Climate Change, 10, e577, https:// doi.org/10.1002/wcc.577.

Efron, B., and R. J. Tibshirani, 1994: An Introduction to the Bootstrap. CRC Press, $456 \mathrm{pp}$.

Freund, M., B. J. Henley, D. J. Karoly, K. J. Allen, and P. J. Baker, 2017: Multi-century cool- and warm-season rainfall reconstructions for Australia's major climatic regions. Climate Past, 13, 1751-1770, https://doi.org/10.5194/cp-13-1751-2017.

Gallant, A. J. E., and J. Gergis, 2011: An experimental streamflow reconstruction for the River Murray, Australia, 1783-1988. Water Resour. Res., 47, W00G04, https://doi.org/10.1029/2010WR009832.

Gergis, J., and Coauthors, 2012: On the long-term context of the 19972009 "Big Dry" in South-Eastern Australia: Insights from a 206year multi-proxy rainfall reconstruction. Climatic Change, 111, 923-944, https://doi.org/10.1007/s10584-011-0263-x.

Grant, S. B., and Coauthors, 2013: Adapting urban water systems to a changing climate: Lessons from the Millennium Drought in southeast Australia. Environ. Sci. Technol., 47, 1072710734, https://doi.org/10.1021/es400618z.

Grose, M., and Coauthors, 2015a: Climate change in Australia projections for Australia's natural resource management regions. Southern Slopes Cluster Rep., 65 pp., https:/www.climatechangeinaustralia.gov.au/ media/ccia/2.1.6/cms_page_media/172/SOUTHERN_SLOPES_ CLUSTER_REPORT_1.pdf.

_ , B. Timbal, L. Wilson, J. Bathols, and D. Kent, 2015b: The subtropical ridge in CMIP5 models, and implications for projections of rainfall in southeast Australia. Aust. Meteor Oceanogr. J., 65, 90-106, https://doi.org/10.22499/2.6501.007.
— J. S. Risbey, A. F. Moise, S. Osbrough, C. Heady, L. Wilson, and T. Erwin, 2017: Constraints on southern Australian rainfall change based on atmospheric circulation in CMIP5 simulations. J. Climate, 30, 225-242, https://doi.org/10.1175/JCLID-16-0142.1.

Guerreiro, S. B., H. J. Fowler, R. Barbero, S. Westra, G. Lenderink, S. Blenkinsop, E. Lewis, and X.-F. Li, 2018: Detection of continental-scale intensification of hourly rainfall extremes. Nat. Climate Change, 8, 803-807, https://doi.org/10.1038/s41558018-0245-3.

Hawkins, E., and R. Sutton, 2011: The potential to narrow uncertainty in projections of regional precipitation change. Climate Dyn., 37, 407-418, https://doi.org/10.1007/s00382-010-0810-6.

Hendon, H. H., E. P. Lim, J. M. Arblaster, and D. L. T. Anderson, 2014: Causes and predictability of the record wet east Australian spring 2010. Climate Dyn., 42, 1155-1174, https://doi.org/10.1007/ s00382-013-1700-5.

Ho, M., A. S. Kiem, and D. C. Verdon-Kidd, 2015: A paleoclimate rainfall reconstruction in the Murray-Darling Basin (MDB), Australia: 2. Assessing hydroclimatic risk using paleoclimate records of wet and dry epochs. Water Resour. Res., 51, 8380 8396, https://doi.org/10.1002/2015WR017059.

Hoerling, M., J. Eischeid, and J. Perlwitz, 2010: Regional precipitation trends: Distinguishing natural variability from anthropogenic forcing. J. Climate, 23, 2131-2145, https://doi.org/ 10.1175/2009JCLI3420.1.

Hope, P., B. Timbal, and R. Fawcett, 2010: Associations between rainfall variability in the southwest and southeast of Australia and their evolution through time. Int. J. Climatol., 30, 13601371, https://doi.org/10.1002/joc.1964.

, and Coauthors, 2015: Seasonal and regional signature of the projected southern Australian rainfall reduction. Aust. Meteor. Oceanogr. J., 65, 54-71, https://doi.org/10.22499/2.6501.005.

— B. Timbal, H. Hendon, M. Ekström, and N. Potter, 2017: A synthesis of findings from the Victorian Climate Initiative (VicCI). Bureau of Meteorology, 68 pp., https:/www.water.vic.gov.au/_ data/assets/pdf_file/0030/76197/VicCI-25-07-17-MR.pdf.

IPCC, 2013: Climate Change 2013: The Physical Science Basis. T. F. Stocker et al., Eds., Cambridge University Press, 1535 pp., https://doi.org/10.1017/CBO9781107415324.

Jones, D., W. Wang, and R. Fawcett, 2009: High-quality spatial climate data-sets for Australia. Aust. Meteor. Oceanogr. J., 58, 233-248, https://doi.org/10.22499/2.5804.003.

Jones, P. W., 1999: First- and second-order conservative remapping schemes for grids in spherical coordinates. Mon. Wea. Rev., 127, 2204-2210, https://doi.org/10.1175/1520-0493(1999)127<2204: FASOCR $>2.0 . \mathrm{CO} ; 2$.

Kiem, A. S., and D. C. Verdon-Kidd, 2010: Towards understanding hydroclimatic change in Victoria, Australia-Preliminary insights into the "Big Dry." Hydrol. Earth Syst. Sci., 14, 433-445, https://doi.org/10.5194/hess-14-433-2010.

Kirtman, B., and Coauthors, 2013: Near-term climate change: Projections and predictability. Climate Change 2013: The Physical Science Basis, T. F. Stocker et al., Eds., Cambridge University Press, 953-1028.

Kociuba, G., and S. B. Power, 2015: Inability of CMIP5 models to simulate recent strengthening of the Walker circulation: Implications for projections. J. Climate, 28, 20-35, https:// doi.org/10.1175/JCLI-D-13-00752.1.

Lim, E. P., and H. H. Hendon, 2015: Understanding and predicting the strong Southern Annular Mode and its impact on the record wet east Australian spring 2010. Climate Dyn., 44, 28072824, https://doi.org/10.1007/s00382-014-2400-5. 
Moise, A., and Coauthors, 2015: Evaluation of CMIP3 and CMIP5 models over the Australian region to inform confidence in projections. Aust. Meteor. Oceanogr. J., 65, 19-53, https:// doi.org/10.22499/2.6501.004.

Potter, N. J., F. H. S. Chiew, H. Zheng, M. Ekström, and L. Zhang, 2016: Hydroclimate projections for Victoria at 2040 and 2065. CSIRO, 58 pp., https://publications.csiro.au/rpr/pub?pid=csiro:EP161427.

— M. Ekström, F. H. S. Chiew, L. Zhang, and G. Fu, 2018: Change-signal impacts in downscaled data and its influence on hydroclimate projections. J. Hydrol., 564, 12-25, https:// doi.org/10.1016/j.jhydrol.2018.06.018.

Power, S., 2014: Expulsion from history. Nature, 511, 38-39, https:// doi.org/10.1038/511038a.

— T. Casey, C. Folland, A. Colman, and V. Mehta, 1999a: Interdecadal modulation of the impact of ENSO on Australia. Climate Dyn., 15, 319-324, https://doi.org/10.1007/s003820050284.

— , F. Tseitkin, V. Mehta, B. Lavery, S. Torok, and N. Holbrook, 1999b: Decadal climate variability in Australia during the twentieth century. Int. J. Climatol., 19, 169-184, https://doi.org/10.1002/ (SICI)1097-0088(199902)19:2<169:AID-JOC356>3.0.CO;2-Y.

_ F. Felage, G. Wang, I. Smith, and G. Kociuba, 2017: Apparent limitations in the ability of CMIP5 climate models to simulate recent multi-decadal change in surface temperature: Implications for global temperature projections. Climate Dyn., 49, 53-69, https://doi.org/10.1007/s00382-016-3326-x.

Rauniyar, S. P., A. Protat, and H. Kanamori, 2017: Uncertainties in TRMM-era multisatellite-based tropical rainfall estimates over the Maritime Continent. Earth Space Sci., 4, 275-302, https://doi.org/10.1002/2017EA000279.

_ S. B. Power, and P. Hope, 2019: A literature review of past and projected changes in Victorian rainfall and their causes, and climate baselines. Bureau of Meteorology Research Rep. 37, 40 pp., http://www.bom.gov.au/research/publications/researchreports/ BRR-037.pdf.

Saft, M., A. W. Western, L. Zhang, M. C. Peel, and N. J. Potter, 2015: The influence of multiyear drought on the annual rainfallrunoff relationship: An Australian perspective. Water Resour. Res., 51, 2444-2463, https://doi.org/10.1002/2014WR015348.
Taylor, K. E., R. J. Stouffer, and G. A. Meehl, 2012: An overview of CMIP5 and the experiment design. Bull. Amer. Meteor. Soc., 93, 485-498, https://doi.org/10.1175/BAMS-D-11-00094.1.

Timbal, B., and R. Fawcett, 2013: A historical perspective on southeastern Australian rainfall since 1865 using the instrumental record. J. Climate, 26, 1112-1129, https://doi.org/ 10.1175/JCLI-D-12-00082.1.

_ J. M. Arblaster, and S. Power, 2006: Attribution of the latetwentieth-century rainfall decline in southwest Australia. J. Climate, 19, 2046-2062, https://doi.org/10.1175/JCLI3817.1.

_ E. Fernandez, and Z. Li, 2009: Generalization of a statistical downscaling model to provide local climate change projections for Australia. Environ. Modell. Software, 24, 341-358, https://doi.org/10.1016/j.envsoft.2008.07.007.

_ - and Coauthors, 2010: Understanding the anthropogenic nature of the observed rainfall decline across South Eastern Australia. CAWCR Tech. Rep. 26, 202 pp., http://www.cawcr.gov.au/ technical-reports/CTR_026.pdf.

— Australia's natural resource management regions. Murray Basin Cluster Rep., 60 pp., https://www.climatechangeinaustralia.gov.au/ media/ccia/2.1.6/cms_page_media/172/MURRAY_BASIN_ CLUSTER_REPORT.pdf.

—, M. Ekström, S. Fiddes, M. Grose, D. Kirono, E.-P. Lim, C. Lucas, and L. Wilson, 2016: Climate change science and Victoria. Bureau Research Rep. 14, 94 pp., https://www.cawcr.gov.au/projects/vicci/ wp-content/uploads/2016/05/BRR-014.pdf.

— , S. Fiddes, and J. R. Brown, 2017: Understanding south-east Australian rainfall projection uncertainties: The influence of patterns of projected tropical warming. Int. J. Climatol., 37, 921-939, https://doi.org/10.1002/joc.5047.

van Vuuren, D. P., and Coauthors, 2011: The representative concentration pathways: An overview. Climatic Change, 109, 5-31, https://doi.org/10.1007/s10584-011-0148-z.

Verdon-Kidd, D. C., and A. S. Kiem, 2009: On the relationship between large-scale climate modes and regional synoptic patterns that drive Victorian rainfall. Hydrol. Earth Syst. Sci., 13, 467-479, https://doi.org/10.5194/hess-13-467-2009. 